University of Louisville

ThinkIR: The University of Louisville's Institutional Repository

Electronic Theses and Dissertations

8-2018

\title{
Cross-validation of the body compassion scale in a sample of women in perimenopause.
}

Jennifer K. Altman

University of Louisville

Follow this and additional works at: https://ir.library.louisville.edu/etd

Part of the Clinical Psychology Commons

\section{Recommended Citation}

Altman, Jennifer K., "Cross-validation of the body compassion scale in a sample of women in perimenopause." (2018). Electronic Theses and Dissertations. Paper 3059.

https://doi.org/10.18297/etd/3059

This Doctoral Dissertation is brought to you for free and open access by ThinkIR: The University of Louisville's Institutional Repository. It has been accepted for inclusion in Electronic Theses and Dissertations by an authorized administrator of ThinkIR: The University of Louisville's Institutional Repository. This title appears here courtesy of the author, who has retained all other copyrights. For more information, please contact thinkir@louisville.edu. 
CROSS-VALIDATION OF THE BODY COMPASSION SCALE

IN A SAMPLE OF WOMEN IN PERIMENOPAUSE

\author{
By \\ Jennifer K. Altman \\ B.A. University of Northern Colorado, 1998 \\ M.A. California State University, Long Beach 2005 \\ M.A. University of Louisville 2016
}

\begin{abstract}
A Dissertation
Submitted to the Faculty of the

College of Arts and Sciences of the University of Louisville

in Partial Fulfillment of the Requirements

for the Degree of
\end{abstract}

Doctor of Philosophy

in Clinical Psychology

Department of Psychological and Brain Sciences

University of Louisville

Louisville, Kentucky

August 2018 
Copyright 2017 by Jennifer K. Altman

All rights reserved 

CROSS-VALIDATION OF THE BODY COMPASSION SCALE

IN A SAMPLE OF WOMEN IN PERIMENOPAUSE

\author{
By \\ Jennifer K. Altman \\ B.A. University of Northern Colorado, 1998 \\ M.A. California State University, Long Beach 2005 \\ M.A. University of Louisville 2016 \\ A Dissertation Approved on
}

May 15, 2017

by the following Dissertation Committee:

Dissertation Chair

Paul Salmon, Ph.D.

Janet Woodruff-Borden, Ph.D.

Benjamin Mast, Ph.D.

Barbara Stetson, Ph.D.

Nancy Theriot, Ph.D. 


\section{DEDICATION}

"Despite illness of body or mind, in spite of blinding despair or habitual belief, who you are is whole...Release everything that isn't your true nature. What's left, the fullness, light and shadow, claim all that as your birthright."

Excerpted from Birthright, by Danna Faulds

To the generations of strong and powerful women in my life, past, present and futurethank you for reminding me of my birthright.

$$
\text { y.k. }
$$




\section{ACKNOWLEDGMENTS}

John Muir so elegantly stated the truth of interconnectedness, "When we try to pick anything out by itself, we find it hitched to everything else in the universe." I am extraordinarily grateful to have been hitched to the universe of $\mathrm{U}$ of $\mathrm{L}$ in my time as a doctoral student. In particular, I would like to thank my mentor, Dr. Paul Salmon, for his support and encouragement of my personal and professional development in the overlap of mindfulness meditation practices and the body. His presence has helped me regain my footing when the path seemed bumpy. I would also like to thank my dissertation committee for their time and valuable comments regarding this project-Dr. Janet Woodruff-Borden for her encouragement to further develop the idea of body compassion and its clinical application, she sparked hope in me at just the right times; Dr. Benjamin Mast for his reminders and encouragement of the many possibilities for greater understanding of body compassion through statistical analyses and development of a line of research, his guidance has been revitalizing; Dr. Barbara Stetson for her support of my professional development and the continued development of body compassion in multiple populations, her collaboration has been energizing; and Dr. Nancy Theriot for the inspiration provided by her work and presence, her enthusiasm is contagious. I am also incredibly grateful for my parents, Doug and Linda Altman — thank you for your constant support and presence in my life. 


\section{ABSTRACT \\ CROSS-VALIDATION OF THE BODY COMPASSION SCALE \\ IN A SAMPLE OF WOMEN IN PERIMENOPAUSE}

Jennifer K. Altman

May 15, 2017

This study is a cross-validation of the Body Compassion Scale (BCS) to confirm its factor structure and to assess concurrent validity in women in perimenopause. Body compassion is a construct developed by the author referring to the level of compassion with which an individual relates to her body. It is based in contemporary mindfulnessand acceptance-based conceptual models. The body is central to the experience of women in perimenopause. Moreover, this important transition has been largely medicalized—with little attention given to experiential aspects of this natural phase of life. A total of 281 women in perimenopause completed online questionnaires assessing their experience of key symptoms/characteristics of perimenopause, body image, and mindfulness- and acceptance-based characteristics, including body compassion. Confirmatory factor analysis of the previously identified three factor solution was performed using structural equation modeling. Overall, results showed good fit to the data. The present study provides support for continued use and application of the BCS as a reliable and valid measure of body compassion. Body compassion may provide an assessment that more accurately captures and addresses the experience of relating to one's body than is 
currently available. Body compassion in women in perimenopause is described and recommendations for future research directions are provided. 


\section{TABLE OF CONTENTS}

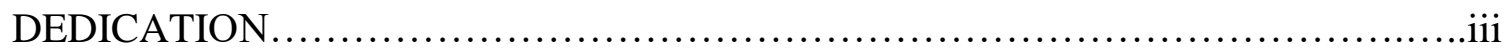

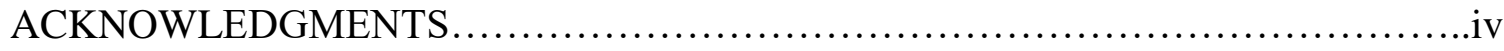

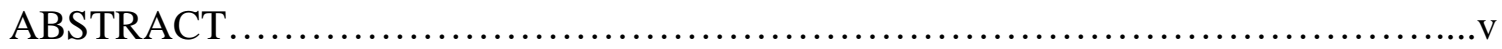

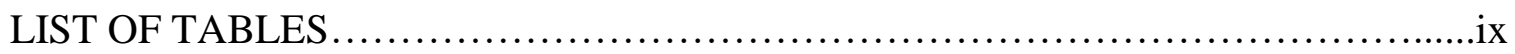

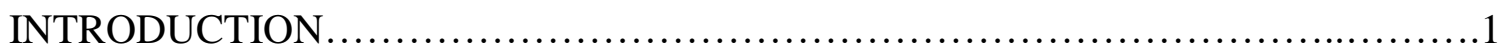

Body Compassion...................................................

Body Image......................................................

Self-Compassion.................................................... 3

Initial Development of the Body Compassion Scale (BCS).................6

Study One - Exploratory Factor Analysis.........................8

Study Two - Confirmatory Factor Analysis.........................15

Body Compassion in Perimenopause....................................22

Rationale.......................................................22

Defining the Menopausal Transition......................................25

Body Image in Perimenopausal Women................................. 34

Self-Compassion in Perimenopausal Women................................ 36

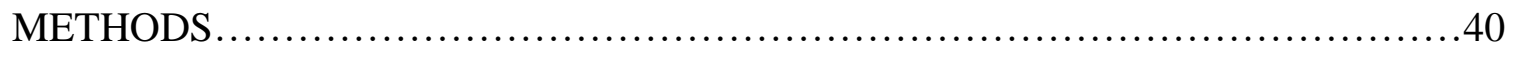

Participants....................................................40

Procedures.......................................................42

Measures.......................................................42

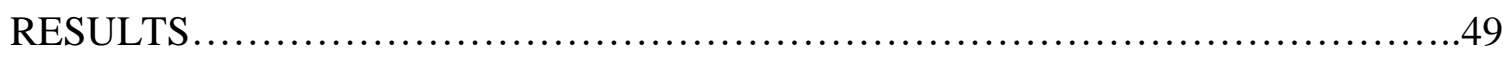




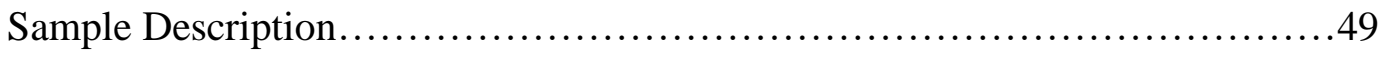

Data Exploration..........................................................56

Confirmatory Factor Analysis............................................60

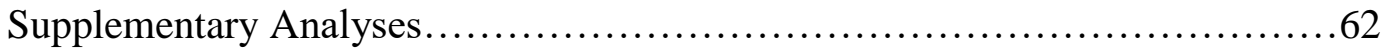

Exploratory Analyses...................................................63

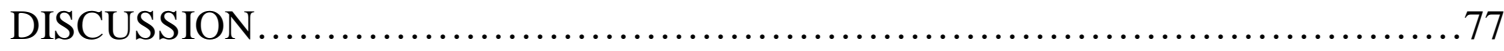

Sample Characteristics................................................... 77

Confirmatory Factor Analysis.............................................. 79

Supplementary Analyses................................................. 82

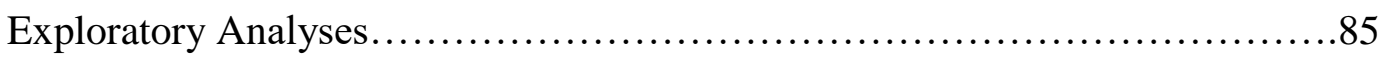

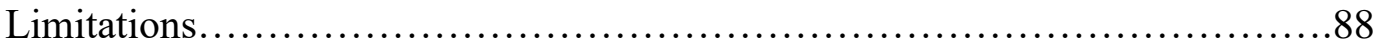

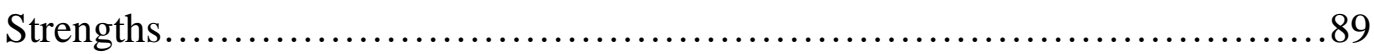

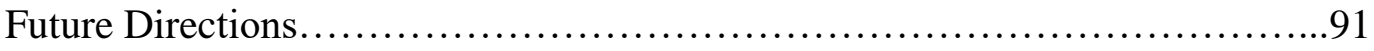

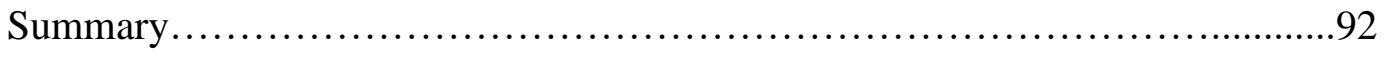

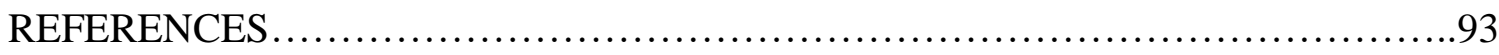

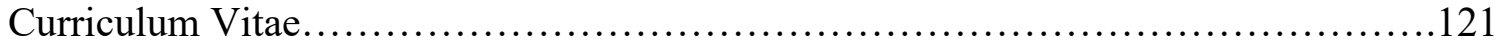




\section{LIST OF TABLES}

TABLE

PAGE

1. Factor structure of 23 BCS items retained from initial pool in Study $1 \ldots \ldots \ldots . . .13$

2. Intercorrelations among body compassion subscales in Study $1 \ldots \ldots \ldots \ldots \ldots \ldots 14$

3. Correlations between body compassion, subscales and other measures in Study 1

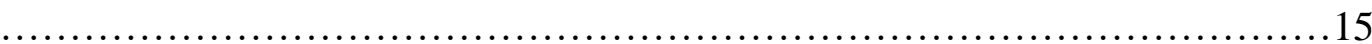

4. Intercorrelations among body compassion subscales in Study $2 \ldots \ldots \ldots \ldots \ldots \ldots . \ldots 18$

5. Correlations between body compassion, subscales and other measures in Study 2

6. Hierarchical regression model predicting exercise frequency..................20

7. Hierarchical regression model predicting Body Mass Index (BMI) .............21

8. Description of marital/partner status and number of children living at home......51

9. Description of education level and annual household income.................52

10. Cross tabulation of number of respondent reports of vasomotor symptoms by

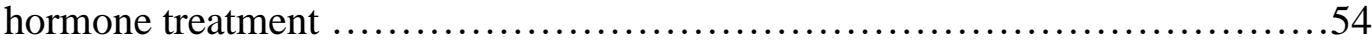

11. Frequencies of chronic illness and chronic pain among the sample..............55

12. CFA Results and Summary Statistics for the Body Compassion Scale (BCS)....58

13. Correlations between body compassion, subscales and other measures....

14. Comparisons of body compassion subscale scores between an undergraduate sample and this sample of women in perimenopause.

15. Correlations between body compassion, subscales and log transformed measures 
16. Bivariate correlations between body compassion subscales and body image and

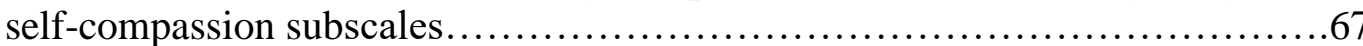

17. Summary of predictor variables retained in models predicting perimenopause

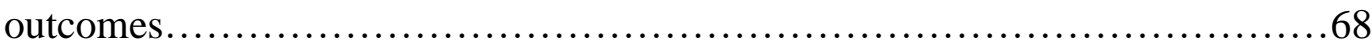

18. Backward regression model predicting vasomotor symptoms with MBSRQ-AS

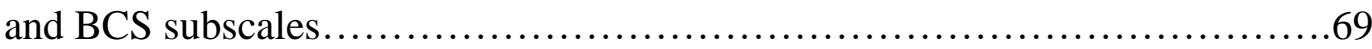

19. Backward regression model predicting vasomotor symptoms with SCS and BCS

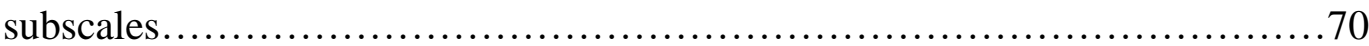

20. Backward regression model predicting sleep quality with MBSRQ-AS and BCS

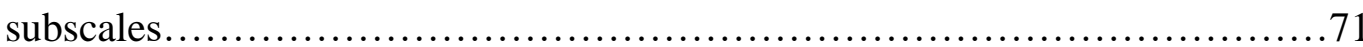

21. Backward regression model predicting sleep quality with SCS and BCS

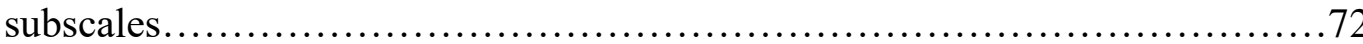

22. Backward regression model predicting depression with MBSRQ-AS and BCS subscales

23. Backward regression model predicting depression with SCS and BCS subscales

24. Backward regression model predicting menopause related quality of life with MBSRQ-AS and BCS subscales

25. Backward regression model predicting menopause related quality of life with SCS and BCS subscales .76 


\section{CHAPTER 1 \\ INTRODUCTION}

Body compassion is a new construct examining how individuals relate to their bodies. The aim of the initial development and validation of the body compassion scale (BCS) was to bridge the two constructs body image and self-compassion, which are grounded in two different theoretical foundations - cognitive behavioral and Buddhist psychology. As mindfulness and acceptance-based (MAB) approaches to inquiry and intervention increase, appropriate and relevant $\mathrm{MAB}$ measures are needed to assess their efficacy. The BCS was developed to provide a measure anchored in a MAB perspective, while still addressing the multidimensionality of body image. The initial development of the BCS utilized exploratory factor analysis to determine the factor structure of the BCS. A follow-up study validating the BCS employed confirmatory factor analysis. Both initial studies in the development and validation of the BCS were completed with large undergraduate samples (Altman, Beacham, Linfield, \& Salmon, 2017). This proposal describes a cross-validation research project of the BCS in a new population, women in perimenopause, to determine if its factor structure holds and to assess concurrent validity.

\section{Body Compassion}

The term "body compassion" represents an effort to establish a bridge between the constructs of body image and self-compassion. The author's conceptualization of body compassion was implemented via application of the three components of selfcompassion (Neff, 2003a) with Cash's (2002) concept of body image as including 
evaluative, cognitive and behavioral components of appearance,

competence/fitness and health/illness. The initial working definition of body compassion was 'the regarding of one's own body, in appearance, competence and health, with mindfulness, kindness and awareness of common humanity" (Altman et al., 2017). This construct provides a conceptualization of body-related disturbances and well-being appropriate to mindfulness and acceptance-based approaches.

Body Image. Body image is a broad construct that envelops the cognitions, emotions, and behaviors an individual has toward her body's appearance, competence and health. The majority of contemporary theory and research on body image is informed by a cognitive-behavioral model (Cash, 2008; Cash, 2011; Cash \& Lavallee, 1997).

There are well established measures assessing various components of body image. The Multidimensional Body Self Relations Questionnaire (MBSRQ) is considered to be the most comprehensive and widely used measure - it taps into each of the aforementioned dimensions of body image (Cash, 2000). More recent work in the study of body image and related constructs resulted in a call for body image measures with a more positive focus, stating that, "A century of body image theory and research has been largely pathology focused, seeking to understand an impaired or dysfunctional body image. A growth in conceptual perspectives and research on positive, adaptive, or healthy body image is essential to the future of the field" (Smolak \& Cash, 2011; p.471). This shift in focus has been associated with the development of measures with a more positive valence such as the Body Appreciation Scale-II (BAS-2) which examines characteristics identified as qualities of positive body image (Tylka and Wood-Barcalow, 2015). The BAS-2 examines characteristics identified as qualities of positive body image, including 
“(a) favorable opinions of the body (regardless of actual physical appearance), (b)

acceptance of the body in spite of weight, body shape, and imperfections, (c) respect of the body by attending to its needs and engaging in healthy behaviors, and (d) protection of the body by rejecting unrealistic body images portrayed in the media" (Avalos, Tylka, \& Wood-Barcalow, 2005, p. 286). The original BAS was recently updated to the BAS-2 to eliminate the need for sex-specific versions and to use more positively-valenced language (Tylka \& Wood-Barcalow, 2015).

However, while measures with a positive focus have recently begun to emerge, there remains a paucity of body image related measures directly reflecting the shift toward mindfulness and acceptance-based approaches. Two notable exceptions are the recently developed Body Image Acceptance and Action Questionnaire (BI-AAQ; Sandoz, Wilson, Merwin, \& Kellum 2013), and the Body Image Psychological Inflexibility Scale (BIPIS; Callaghan, Sandoz, Darrow, \& Feeney, 2015). Both the BI-AAQ and the BIPIS are centered in the MAB approach of Acceptance and Commitment Therapy. Both are focused on the desired outcome of higher levels of psychological flexibility, versus a more broadly defined MAB focus/outcome.

Self-Compassion. Self-compassion is framed as a positive self-attitude, counter to self-esteem and its associated tendencies towards self-centeredness and downward social comparison. Self-compassion has been defined by Kristen Neff as consisting of three components and their inverses: self-kindness (versus self-judgment), common humanity (versus isolation), and mindfulness (versus over-identification; Neff, 2003a). Neff (2003a) has described self-compassion as "being open to and moved by one's own suffering, experiencing feelings of caring and kindness toward oneself, taking an 
understanding, nonjudgmental attitude toward one's inadequacies and failures, and recognizing that one's own experience is part of the common human experience" (p. 224).

Self-kindness is an active component of self-compassion which involves being sensitive to, and having empathy for, one's own suffering and experience-offering warmth, patience and forgiveness to all of one's thoughts, feelings, tendencies and behaviors (Barnard \& Curry, 2011). Its counterpart, self-judgment, is also an active stance and is just the opposite of self-compassion — being hostile, disparaging and critical of one's self (Neff, 2003a).

Common humanity is a component of self-compassion that is clearly rooted in Buddhist thought and the idea that all human beings are interconnected (Barnard \& Curry, 2011). It is the recognition of this interconnectedness and the shared human experience that is reflected in the notion of self-compassion, with an allowing and forgiveness of one's inevitable human imperfections (Neff, 2003a). The opposite of common humanity is a sense of isolation and being cut-off from others, often withdrawing in an effort to hide the inadequacies of one's "true self" (Barnard \& Curry, 2011).

The mindfulness component of self-compassion is described by Neff (2003b, p. 224) as an "equilibrated mental perspective." It is a nonjudgmental observational stance of one's thoughts, feelings and experiences (Neff, 2003b)—one of awareness, attention to, and acceptance of the present moment (Shapiro, Brown, \& Biegel, 2007). As conceptualized by Neff (2003a), its opposite is overidentification, which is a process whereby “one's sense of self becomes so immersed in one's subjective emotional 
reactions that it becomes difficult to distance oneself from the situation and adopt a more objective perspective" (p. 224).

The idea of relationship to thought/emotion/experience is inherent in Buddhist psychology and contemporary aspects of mindfulness (Brach, 2003; Salzberg, 1997). This relationship is, in part, captured via the self-compassion scale, a valid and reliable 26-item measure that is significantly related with less depression and anxiety, and with greater life satisfaction (Neff, 2003b).

Interest in self-compassion and use of the self-compassion scale has increased markedly in the past decade and has been associated with meaningful outcomes and multiple facets of human experience, such as: physiological functioning (Arch et al., 2014), psychological well-being (Hall, Row, Wuensch, \& Godley, 2013), trauma (Seligowski, Miron, \& Orcutt, 2014), alcohol use (Brooks, Kay-Lambkin, Bowman, \& Childs, 2012), coping (Sirois, Molnar, \& Hirsch, 2015), resilience (Neff \& McGeehee, 2010), motivation (Williams, Stark, \& Foster, 2008), interpersonal concerns (Yarnell \& Neff, 2013), health behaviors (Sirois, Kitner, \& Hirsch, 2015), athletics (Mosewich, Kowalski, Sabiston, Sedgwick, \& Tracy, 2011), and many more.

The research on self-compassion consistently reports a strong association between mental health and self-compassion (Barnard \& Curry, 2011)—including depression, anxiety and stress, the relationship with which a large effect size has been reported in a recent meta-analysis (MacBeth \& Gumley, 2012). Furthermore, the research on selfcompassion has demonstrated its relationship with components of positive psychology, such as happiness, positive affect, optimism, wisdom, curiosity, and personal initiative (Neff, Rude, \& Kirkpatrick, 2007). 
Initial Development of the Body Compassion Scale (BCS). The BCS was designed to bridge the constructs of body image and self-compassion. The BCS was developed for use in research, clinical assessment and intervention - to examine the role of body compassion in understanding, preventing, and enhancing health promoting behaviors, psychological wellbeing and/or quality of life. Thus far, the initial development and validation of the BCS has been completed. See Figure 1, a-g. 


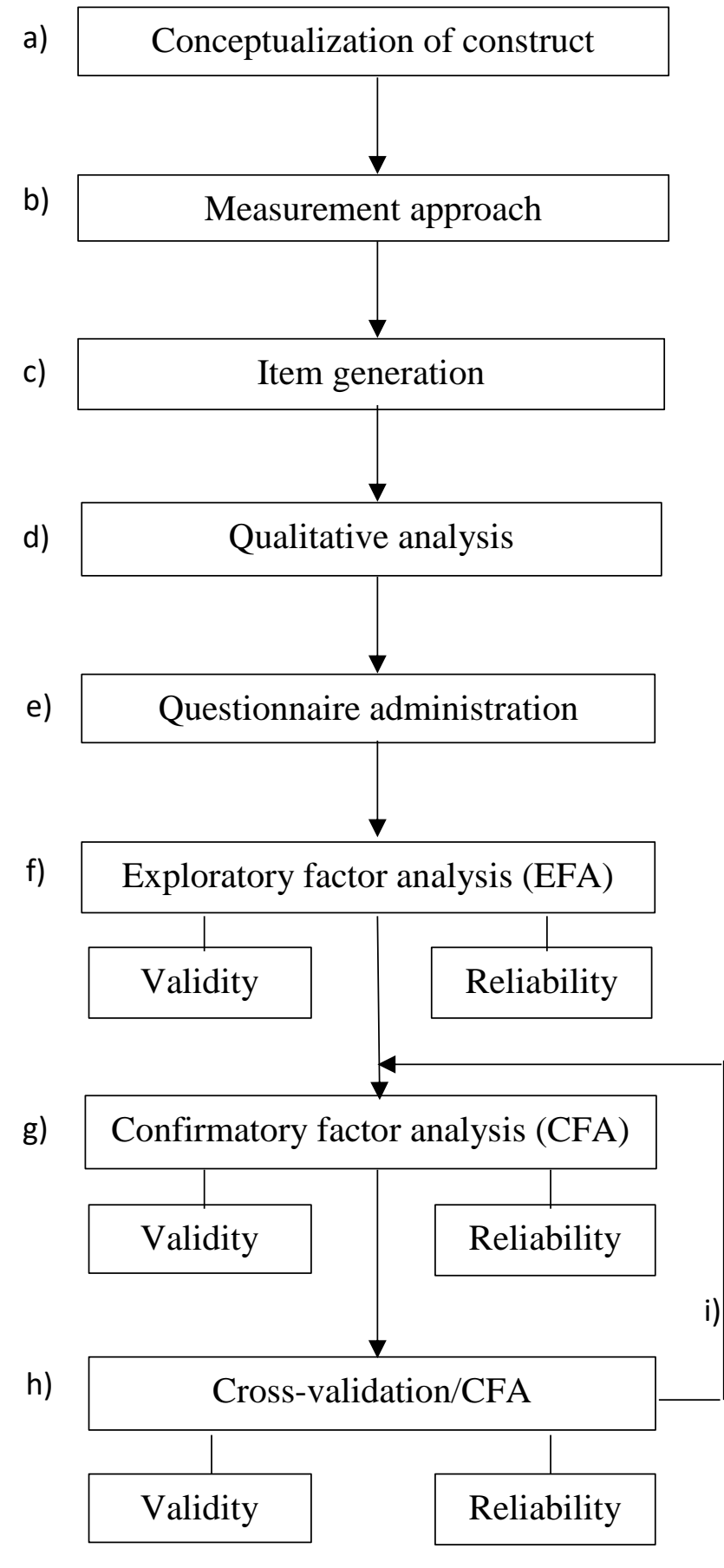

a) Clark and Watson's (1995, p.310) "critical first step" of scale development - thoroughly detailing conceptualization of body compassion.

b) Determine approach to measurement of body compassion (Anastasi \& Urbina, 1997): Likerttype scaling self-report questionnaire, the body compassion scale (BCS).

c) Item development: Construct a large quantity of items representing the content of each section of each subscale of the BCS (Dawis, 1987).

d) Qualitative analysis: judge each item for clarity, simplicity of language, social desirability, transparency and palatability. Also assess the items for face validity (Green, 1981).

e) Administer the items developed for the BCS to a minimum of 100 participants (Dawis, 1987).

f) Exploratory Factor Analysis (EFA). Determine factor structure of BCS. Establish construct validity by showing concurrent validity with other relevant constructs. Establish reliability by showing internal consistency through examining the intercorrelations among the items, producing the reliability coefficient alpha (Green, 1981).

g) Confirmatory Factor Analysis (CFA; Anderson \& Gerbing, 1988). Validate the BCS on a new sample by replicating the factor structure found in EFA.

h) Cross-validation/CFA. Test the factor structure of the BCS in a new population. Continue to establish reliability and validity, with a focus on content validity and construct validity, ensuring the BCS "can be shown to make scientific and conceptual sense" (Green, 1981, p. 1006).

i) Ongoing process of refinement (Smith \& McCarthy, 1995). Construct validity must constantly be revisited with each new population, setting and task to which the BCS is applied. Cronbach and Meehl (1955) suggest this is an open-ended process of test evaluation in which theory and research findings are continually compared and re-evaluated. 
The initial development of the BCS was comprised of two studies. IRB approval was obtained from each of the data collection sites. Participants signed up for the studies online through each university's psychology department's organized undergraduate research program. Upon signing up participants received a link to Survey Monkey where the study website contained a description of the study, procedures and preamble informed consent. The introductory page was followed by the collection of self-report questionnaires for each study, and a concluding page, which thanked participants.

To control for potential error associated with careless or nonsensical responding, the authors randomly inserted three items in each survey stating, "This item is here to be sure you are paying attention as you respond. If you just read this, choose ' 5 '” (Tylka \& Wood-Barcalow, 2015). This resulted in the invalidation and elimination of 59 participant surveys in study one, and 85 participant surveys in study two. In addition, surveys which were less than $90 \%$ complete were excluded from analyses.

Study One-Exploratory Factor Analysis. The primary aims of study one were to 1) generate and select potential items for the BCS; and 2) conduct a preliminary appraisal of the resultant scale's validity.

Method. The structure of the Body Compassion Scale was modeled after the selfcompassion scale (Neff, 2003b) while addressing the multiple dimensions of body image (Cash, 2000). Eighty-three theoretically based Likert-style items were generated from the initial definition of body compassion, 'the regarding of one's own body, in appearance, competence and health, with mindfulness, kindness and awareness of common humanity,' representing content of each of the three subscales of selfcompassion (mindfulness vs. over-identification, kindness vs. judgment, common 
humanity vs. isolation) (Neff, 2003b). Within each subscale, the three major components of the physical self from body image assessment - appearance, competence, and health were also reflected (Cash, 2002).

Following the generation of these items, the initial phase of item selection involved qualitative analysis_-judging each item for clarity, simplicity of language, social desirability, transparency and palatability and, finally, face validity (Green, 1981). Given the utilization of the overall form and language from two well-established constructs and their measures (self-compassion, the self-compassion scale (SCS) (Neff, 2003b); body image, MBSRQ (Cash, 2002)), small 2-3 person focus groups were not conducted as Neff (2003b) had in the early stages of developing the self-compassion scale.

Participants. Participants were 662 undergraduates who received course credit for online survey completion. Participants had an average age of 20.49. The sample was $28.8 \%$ male and $70.8 \%$ female. They were $76.9 \%$ White, $11.6 \%$ Black, $4.4 \%$ Asian, and 3.5\% Hispanic. The average Body Mass Index (BMI) was 24.13.

There were 89 cases with missing values for one $(n=72)$, two $(n=12)$, three $(n=$ 4), or five $(n=1)$ items. Person-mean $\mathrm{z}$-scores were computed for all valid items scores, then scores were imputed for the missing values. One case with missing values for 15 items was dropped, resulting in a total final sample size of $\mathrm{N}=662$.

\section{Measures.}

Demographic Questionnaire. Each participant was asked to provide general demographic and health related information including such items as age, ethnicity, racial origin, and various lifestyle factors (e.g. smoking, alcohol use, etc.). 
Body Compassion Scale (BCS). The initial pool of 83 BCS items were written to capture mindfulness, kindness and common humanity within appearance, competence and health. This created 9 initial subscales, which were worded to represent the positive and negative aspect of each component. Instructions for use of the BCS are similar to the instructions for both the SCS and the MBSRQ: that it is appropriate for ages 15 and up, with a minimum of an eighth grade reading level (Cash, 2002; Neff, 2003). Participants were instructed to indicate how often they believe or behave in the stated manner on each of the items on a scale of 1 ("almost never") to 5 ("almost always").

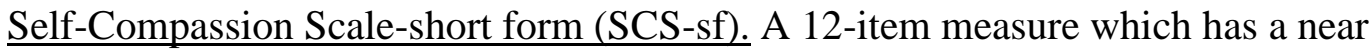
perfect correlation with the long Self-Compassion scale. Participants were instructed to indicate how often they behave in the stated manner on each of the items on a scale of 1 (“almost never") to 5 (“almost always") (Raes, Pommier, Neff, \& Van Gucht, 2011).

Body Image-Acceptance and Action Questionnaire (BI-AAQ). The BI-AAQ is a 12-item measure of body image flexibility (the capacity to experience the ongoing perceptions, sensations, feelings, thoughts, and beliefs associated with one's body fully and intentionally while pursuing chosen values), a potential change process in acceptance-oriented treatments (Sandoz, Wilson, Merwin, \& Kellum, 2013).

Eating Attitudes Test-26 (EAT-26). The EAT-26 is a 26-item measure used to assess disordered eating behavior (Garner, Olmsted, Bohr, \& Garfinkel, 1982).

Procedures. Upon accessing the survey website participants completed a collection of self-report questionnaires including a demographics questionnaire, the BCS, the SCS-sf, the BI-AAQ, and the EAT-26, in that order.

Results. 
Exploratory Factor Analysis. Preliminary exploratory factor analysis resulted in a Kaiser-Meyer-Olkin Measure of Sampling Adequacy of 0.929, showing enough common variability between items to warrant exploratory factor analysis. Bartlett's test of Sphericity was significant $(\chi 2(3403)=26,870.18, \quad p<0.001)$, indicating the R-matrix is not an identity matrix; and initial communalities range from 0.37 to 0.76 , suggesting acceptable shared variance between items. The minimum number of participants needed for an exploratory factor analysis is five participants per item (Gorsuch, 1983); therefore, the current sample of 662 (greater than $5 \times 83$ items $=415$ ) had sufficient power to provide useful data in evaluation of this new instrument.

Parallel analysis indicated that although five components had eigenvalues greater than 1.0, only four components had eigenvalues greater than what would be found in $95 \%$ of random rearrangements of the data. In addition, a Varimax rotated solution with Kaiser normalization of the first four components had only two of the 83 items loading substantially on the fourth factor, indicating that a three factor solution, accounting for $51.9 \%$ of the variance was the best. A Varimax rotation with Kaiser normalization converged in five iterations. To create a reasonably brief scale that could be used in many settings, only items with minimum loadings of .60 on one factor were retained in the final factor structure, resulting in 23 final items. The three factors were labeled: Defusion, Common Humanity, and Acceptance. See Figure 2. The factor structure is shown in Table 1. 


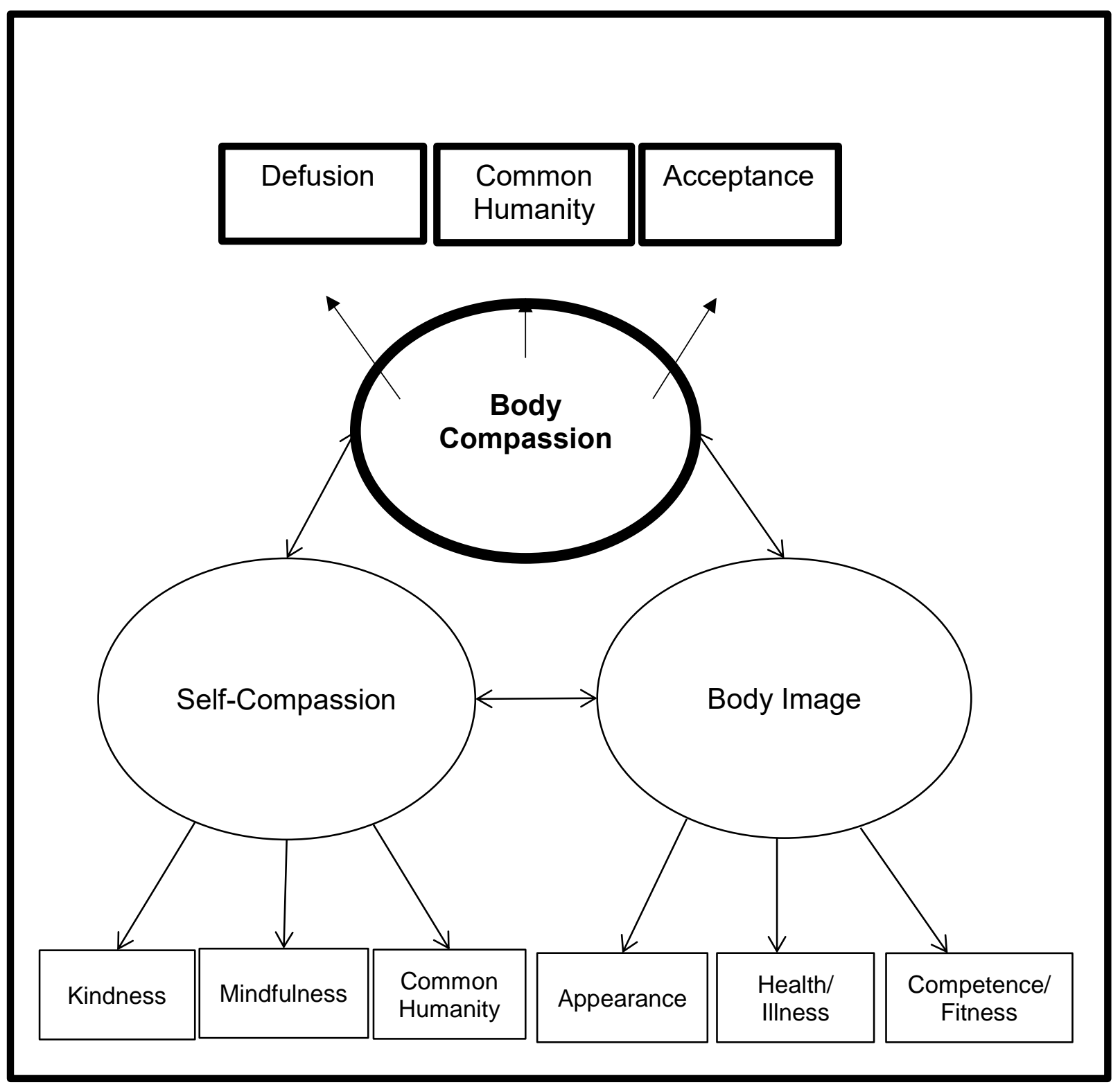

Figure 2. Schematic of theoretical underpinnings informing the factors of the Body Compassion Scale 


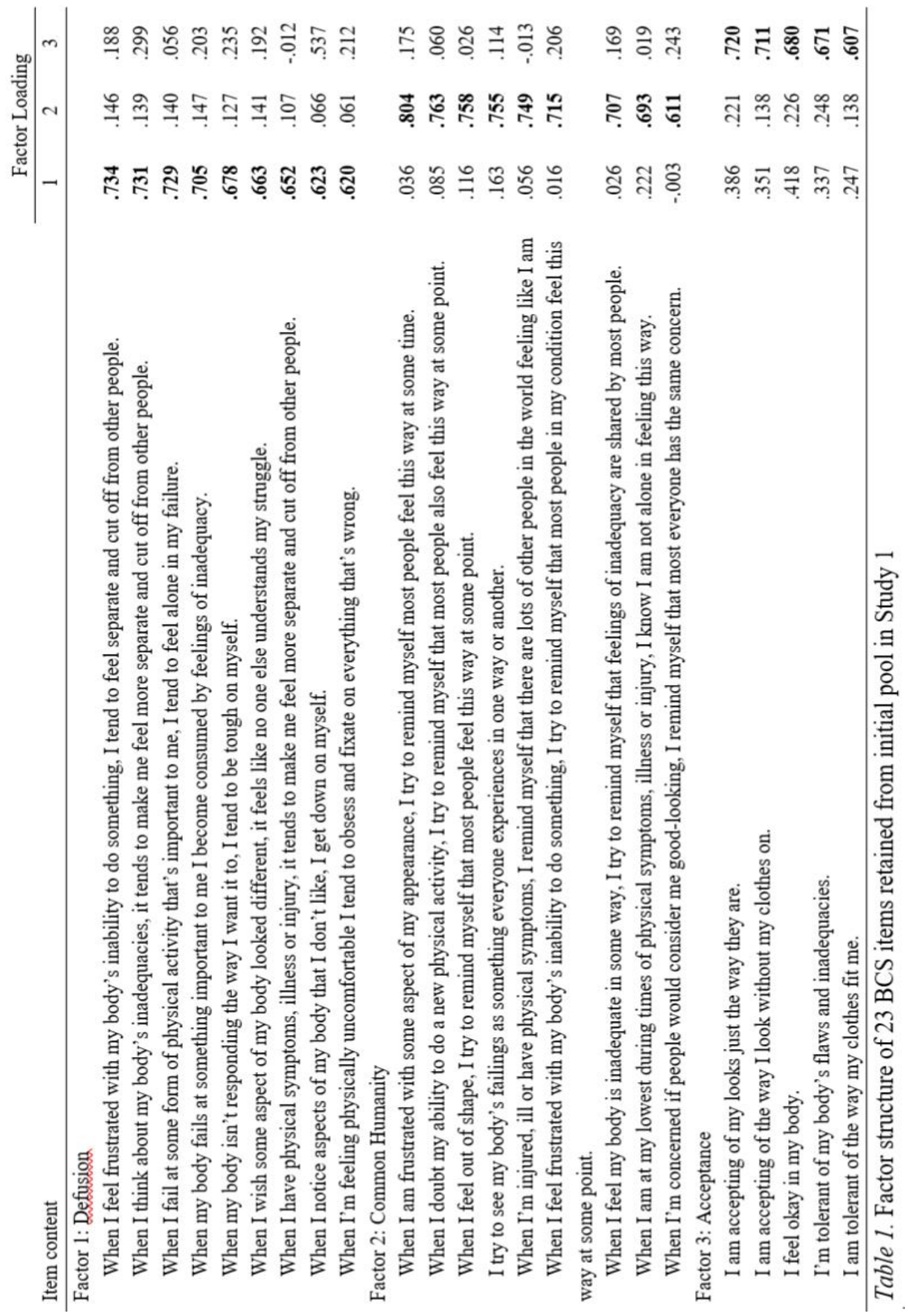


Calculation and descriptive statistics. Body compassion scores were calculated by reverse-scoring the defusion subscale, scoring the common humanity and acceptance subscales, and summing responses on the 23-item BCS. BCS scores ranged from 26 to 114 , with a mean of 72.16 and a standard deviation of 15.83. The distribution of BCS scores was normally distributed $($ Kolmogorov-Smirnov $=.03, \mathrm{p}=.152)$.

Internal Consistency and Intercorrelations. The following alpha coefficients were obtained for the three subscales/factors of the body compassion scale, suggesting good internal consistency: Defusion $=.90$, Common Humanity $=.91$, Acceptance $=.88$. Intercorrelations among the factors/subscales can be seen in Table 2. All are significantly positively correlated with each other, with $r$ 's ranging from .29 (Defusion with Common Humanity) to .67 (Defusion with Acceptance).

Table 2.

Intercorrelations among body compassion subscales in Study 1

\begin{tabular}{lccc}
\hline & Defusion & Common Humanity & Acceptance \\
\hline Defusion & --- & $.293^{* *}$ & $.665^{* *}$ \\
Common Humanity & & --- & $.392^{* *}$ \\
Acceptance & & & --- \\
\hline$* * p<.001$. & & \\
\multicolumn{1}{c}{ Construct validity. } & &
\end{tabular}

Concurrent validity. Correlations between body compassion and other relevant constructs are shown in Table 3. All correlations were in the expected directions and were statistically significant. Most were moderate to large. These findings indicate that body compassion and its factors/subscales show predicted relationships with other variables. 
Table 3.

Correlations between body compassion, subscales and other measures in Study 1

\begin{tabular}{lcccc}
\hline Measures & $\begin{array}{c}\text { Body } \\
\text { Compassion } \\
\text { Total }\end{array}$ & Defusion & $\begin{array}{c}\text { Common } \\
\text { Humanity }\end{array}$ & Acceptance \\
\hline $\begin{array}{l}\text { Predicted positive correlations } \\
\quad \text { SCS-sf }\end{array}$ & $.790^{* *}$ & $.717^{* *}$ & $.491^{* *}$ & $.677^{* *}$ \\
$\quad$ BI-AAQ & $.689^{* *}$ & $.726^{* *}$ & $.207^{* *}$ & $.728^{* *}$ \\
$\begin{array}{l}\text { Predicted negative correlations } \\
\text { BMI }\end{array}$ & $-.208^{* *}$ & $-.174^{* *}$ & $-.082^{*}$ & $-.266^{* *}$ \\
EAT-26 & $-.550^{* *}$ & $-.543^{* *}$ & $-.250^{* *}$ & $-.521^{* *}$ \\
\hline
\end{tabular}

$* p<.05 . * * p<.01$.

Study 2-Confirmatory Factor Analysis. The main objectives of study two were to 1) confirm the factor structure identified in study one; 2) evaluate the BCS as a valid and reliable scale that accurately assesses levels of body compassion; and to 3) examine psychosocial factors associated with different levels of body compassion.

\section{Method.}

Participants. Participants were 256 undergraduates who were recruited through the psychology department's organized research program for class credit at a Midwestern metropolitan University. Participants were excluded from this study if they had participated in study one. Participants had an average age of 20.24 years and the mean BMI was 24.26. The sample was $27.9 \%$ male and $72.1 \%$ female. They were $81.4 \%$ White, 8.5\% Black, 4.3\% Asian, 2.7\% Hispanic, and 0.39\% American Indian.

There were 17 cases with missing values for one $(n=16)$ or two $(n=1)$ items. Person-mean z-scores were computed for all valid items scores, then scores were imputed for the missing values. Two cases with missing values for 13 of the items were deleted, resulting in a total final sample size of $\mathrm{N}=256$. 
Measures. In study two, the Demographic Questionnaire, the twenty-three-item BCS developed in study one, the SCS-sf, the BI-AAQ and the EAT-26 were included in a packet of measures which also included the following:

Body Compassion Scale (BCS). A 23-item measure consisting of a total score and three subscales (Defusion, Common Humanity, and Acceptance). Internal consistencies (Cronbachs alpha) for this sample are: .918, .907, and .871 respectively.

Five Facet Mindfulness Questionnaire (FFMQ). A 39-item measure consisting of five subscales: Observing, Describing, Acting with Awareness, Non-judging of inner experience, and Non-reactivity to inner experience (Baer, Smith, Hopkins \& Krietemeyer, \& Toney, 2006).

Positive and Negative Affect Scales (PANAS). The PANAS is a 20-item selfreport measure of positive and negative affect. Each item is a mood state adjective (i.e. "distressed") and is rated on a scale of 1 (very slightly or not at all) to 5 (extremely). The negative items are summed to provide a NA result for negative affect, and the positive items are summed to provide a PA result for positive affect. (Watson, Clark, \& Tellegen, 1988). This instrument was validated in studies using affect scales in relationship to psychopathology (Huebner \& Dew, 1995).

Procedures. Upon accessing the survey website participants completed a collection of self-report questionnaires including a demographics questionnaire, the BCS, the FFMQ, the SCS-sf, the BI-AAQ, the EAT-26, the GLTEQ, and the PANAS, in that order. 
Results.

Confirmatory Factor Analysis. Given the three factor solution identified in study one, a Confirmatory Factor Analysis (CFA) was conducted to examine the three factor solution. The three factor CFA solution was tested with Structural Equation Modeling, using AMOS software version 22. Overall, results showed good fit to the data. Browne and Cudeck (1993) suggest that the root mean square error of approximation (RMSEA) is one of the most useful indices of model fit, partly because it does not reward including additional parameters. For the three factor CFA model, the RMSEA $=0.08(90 \% \mathrm{CI}=$ 0.071-0.085). As Browne and Cudeck note, "a value of about 0.08 or less for the RMSEA would indicate a reasonable error of approximation" (1993, p.144). Another criterion for a good fit is observed chi square divided by degrees of freedom equal to 2.0 or less. In this sample, the value was $2.62($ Chi-square $=594.2$, df $=227)$ which approached meeting the 2.0 criterion. The fit can be improved by allowing the errors for 3 pairs of items to be correlated - meaning that people tend to answer several pairs of questions in similar ways. The pairs are: Items 8 and 10, items 20 and 21, and items 21 and 22. When those changes are made, Chi-Square $=493.4, \mathrm{df}=224, \mathrm{RMSEA}=.069$. The value of the observed chi square divided by degrees of freedom improves to 2.20. A one factor solution $($ Chi-square $=1832.4, \mathrm{df}=230$, Ratio: 8.0, RMSEA $=$ 0.165 ) and a two factor solution (Chi-square $=890.5$, df $=229$, Ratio: 3.9, RMSEA $=$ 0.106) were also examined. The three factor solution is a significantly better fit than either the one or the two factor. In addition, the other fit indicators indicate the one and two factor solutions are not even close to an adequate fit to the data. 
Calculation and descriptive statistics. The central tendency and spread of the distribution of BCS scores was again examined and scores ranged from 30 to 115 with a mean of 72.88 and a standard deviation of 16.46 . Consistent with study one, the distribution of BCS scores was normally distributed (Kolmogorov-Smirnov $=.056, \mathrm{p}=$ $.053)$.

\section{Reliability.}

Internal consistency and Intercorrelations. The 23-item version of the BCS was again examined for internal consistency. The following alpha coefficients were obtained for the three subscales/factors of the body compassion scale, demonstrating excellent internal consistency: Defusion $=.92$, Common Humanity $=.91$, Acceptance $=.87$. As in study 1 , all were significantly positively correlated with each other, with $r$ 's ranging from .25 (Defusion with Common Humanity) to .61 (Defusion with Acceptance). See Table 4 . The Cronbachs alpha of 0.92 for all 23 items is excellent, supporting use of a total score.

Table 4.

Intercorrelations among body compassion subscales in Study 2

\begin{tabular}{lccc}
\hline & Defusion & Common Humanity & Acceptance \\
\hline Defusion & --- & $.245^{* *}$ & $.606^{* *}$ \\
Common Humanity & & --- & $.432^{* *}$ \\
Acceptance & & & --- \\
\hline$* * p<.001$. & & &
\end{tabular}




\section{Validity.}

Concurrent Validity. Body compassion was positively related to body image flexibility and self-compassion, and negatively related to body mass index and disordered eating in study one. As seen in Table 5, these relationships were replicated in the current study. In addition, body compassion scores were positively related to mindfulness, positive affect, exercise frequency and negatively related to negative affect. See Table 5.

Table 5.

Correlations between body compassion, subscales and other measures in Study 2

\begin{tabular}{lccll}
\hline Measures & $\begin{array}{c}\text { Body } \\
\text { Compassion } \\
\text { Total }\end{array}$ & Defusion & $\begin{array}{c}\text { Common } \\
\text { Humanity }\end{array}$ & Acceptance \\
\hline $\begin{array}{l}\text { Predicted positive } \\
\text { correlations }\end{array}$ & & & & \\
$\quad$ SCS-sf & $.747^{* * *}$ & $.691^{* * *}$ & $.467^{* * *}$ & $.580^{* * *}$ \\
$\quad$ BI-AAQ & $.669^{* *}$ & $.686^{* *}$ & $.248^{* *}$ & $.652^{* *}$ \\
FFMQ & $.378^{* * *}$ & $.396^{* * *}$ & $.169^{*}$ & $.320^{* * *}$ \\
PA & $.354^{* * *}$ & $.246^{* * *}$ & $.253^{* * *}$ & $.371^{* * *}$ \\
GLTEQ & -.066 & -.008 & -.076 & -.094 \\
Predicted negative & & & & \\
correlations & & & & \\
$\quad$ BMI & $-.281^{* * *}$ & $-.201^{* *}$ & $-.192^{* *}$ & $-.298^{* * *}$ \\
$\quad$ EAT-26 & $-.415^{* * *}$ & $-.428^{* * *}$ & -.126 & $-.431^{* * *}$ \\
$\quad$ NA & $-.436^{* * *}$ & $-.496^{* * *}$ & $-.180^{* *}$ & $-.312^{* * *}$ \\
\hline$p<.05 . * * p<.01 . * * * p<.001$ & & & &
\end{tabular}


Predictive Validity. In the prediction of exercise frequency over a 7-day period, with Body Mass Index, Positive and Negative Affect Scale and Body Compassion Scale-Total score included in the model, only positive affect $($ Beta $=-.414)$ and body compassion (Beta $=.157)$ accounted for significant amounts of total variance (See Table 6). In predicting BMI, with Positive and Negative Affect, Five Facet Mindfulness Questionnaire-Total score and Body Compassion Scale-Total score, only body compassion accounted for a significant amount of the variance $($ Beta $=-.288)$ in the model (See Table 7).

Table 6.

Hierarchical regression model predicting exercise frequency.

\begin{tabular}{|c|c|c|c|c|}
\hline & Std. beta & $\mathrm{t}$ & $\mathrm{R}^{2}$ & ChangeR $^{2}$ \\
\hline BMI & .095 & $1.483(.011)$ & .009 & .009 \\
\hline BMI & .072 & $1.205(.010)$ & \multirow[t]{2}{*}{.146} & \multirow[t]{2}{*}{$.137 * * *$} \\
\hline PANAS - Positive & -.371 & $-6.199(.006) * * *$ & & \\
\hline BMI & .070 & $1.174(.010)$ & \multirow[t]{3}{*}{.147} & \multirow[t]{3}{*}{.001} \\
\hline PANAS - Positive & -.367 & $-6.098(.006) * * *$ & & \\
\hline PANAS - Negative & .034 & $.562(.006)$ & & \\
\hline BMI & .107 & $1.728(.011)$ & \multirow[t]{4}{*}{.163} & \multirow[t]{4}{*}{$.016 *$} \\
\hline PANAS - Positive & -.414 & $-6.515(.007) * * *$ & & \\
\hline PANAS - Negative & .095 & $1.433(.006)$ & & \\
\hline BCS (Total) & .157 & $2.166(.003)^{*}$ & & \\
\hline \multicolumn{5}{|c|}{$\begin{array}{l}\text { Note: DV - Exercise frequency item GLTEQ; Ivs: Body Mass Index (BMI); Positive and } \\
\text { Negative Affect Scale (PANAS); Body Compassion Scale-Total score (BCS); Values in } \\
\text { parentheses are standard errors. } \\
*_{p}<.05, * * p<.01, * * * p<.001 .\end{array}$} \\
\hline
\end{tabular}


Table 7.

Hierarchical regression model predicting Body Mass Index (BMI)

\begin{tabular}{lcccc}
\hline & Std. beta & $\mathrm{t}$ & $\mathrm{R}^{2}$ & ChangeR $^{2}$ \\
\hline Positive affect & -.062 & $-.921(.041)$ & .004 & .004 \\
Positive affect & -.052 & $-.768(.042)$ & .010 & .006 \\
Negative affect & .077 & $1.125(.036)$ & & \\
Positive affect & -.046 & $-.647(.044)$ & .010 & .000 \\
Negative affect & .068 & $.915(.040)$ & & \\
Mindfulness & -.021 & $-.269(.050)$ & & \\
& & & & \\
Positive affect & .033 & $.457(.045)$ & .067 & $.057^{* * *}$ \\
Negative affect & -.033 & $-.423(.041)$ & & \\
Mindfulness & .017 & $.219(.049)$ & & \\
Body compassion & -.288 & $-3.634(.021)^{* * *}$ & & \\
\hline
\end{tabular}

Note: DV : Body Mass Index (BMI), Ivs: Positive and Negative Affect Scale (PANAS); Five Facet Mindfulness Questionnaire - Total score (FFMQ), Body Compassion Scale-Total score (BCS); Values in parentheses are standard errors.

$* p<.05, * * p<.01, * * * p<.001$.

Summary. Thus far the foundational steps of scale development have been completed with the BCS (See Figure 1, a-g). The results suggest that the BCS is a valid and reliable scale. The next step of the BCS' development is to complete a crossvalidation in a new population sample (See Figure 1, h). Body compassion has widespread applicability in populations ranging from persons with chronic illness to fitness related application in apparently healthy persons and athletes. The ultimate utility of the BCS will be its ability to predict outcomes and guide interventions for health and health-related behavior change beyond what has been previously demonstrated via other constructs such as self-compassion (Neff, 2003b) and body image flexibility (Sandoz et al., 2013). Women in perimenopause is one population in which body compassion may have especially high utility. Following is an overview of this population and the 
relevance of conducting a cross-validation of the BCS in a sample of women in perimenopause.

\section{Body Compassion in Perimenopause}

Body compassion is applicable to a wide range of populations. Due to the centrality of the body in the experience of perimenopause, one relevant population for testing body compassion and running a cross-validation of the BCS is women in perimenopause. Following is a brief overview of the literature on perimenopause, body image, the impact of perimenopausal symptoms on body image, and self-compassion as it relates to the experience of perimenopause, associated symptoms and health outcomes. This review lays the groundwork for body compassion as the synthesis of body image and self-compassion in the approach to the perimenopausal experience, and the BCS as a viable measure to capture this distinct element of that experience. Self-compassion is a general construct referring to the self, however, the question remains, how do you specifically treat the physical manifestations (i.e., the body) with care and compassion? Body compassion is a construct that may inform the subsequent evolution of interventions specific to experiences based in the body. This cross-validation of the BCS in women in perimenopause is a first step in testing its validity and usefulness in populations beyond undergraduate students.

Rationale. Body compassion describes the way an individual relates to her body. This relationship with one's own body has important implications for health outcomes and well-being. The body is constantly in motion, shifting internally and externally throughout the lifespan. Cash (2011) has described the body as "a 'moving target,' which entails an ongoing process of adaptation to physical changes, for better or for worse" ( $p$. 
42). This statement is particularly relevant to the experience many women have in traversing the menopausal transition, namely the perimenopausal stage. Yet, despite the complexities of this time in a woman's life, the research on perimenopause-its symptoms and health outcomes - and the way women relate to their bodies and to their experience of their bodies during this time, is lacking, both in research and clinical applications. Women in perimenopause were selected for purposes of cross-validation of the BCS for a number of reasons.

Somatic experiences and distress. Perimenopause is the span of time in a woman's reproductive development directly preceding menopause and is characterized by fluctuating hormone levels and overall decline in circulating estrogen (Rasgon, Shelton, \& Halbreich, 2005). For many women perimenopause is accompanied by a range of uncomfortable somatic experiences which may cause significant distress and deleterious health outcomes, including: hot flashes, sleep disturbances, and depressive symptomatology (Pearce, Thogersen-Ntoumani, \& Duda, 2014). Hypotheses regarding the mechanisms that lead to distress for some women and not others in response to the same symptoms, range from strictly biological explanations (e.g., hormonal fluctuations; Freeman, Sammel, Lin, \& Nelson, 2006) to explanations focused on social support as the primary factor in successful outcomes (Koch \& Mansfield, 2004).

Insufficient research. In the United States alone, over the past decade estimates have expected approximately 1.7 million women to enter perimenopause each year (Soares, Prouty, Born, \& Steiner, 2005). Despite the large numbers of women entering the approximately decade-long transition process, the research on the mechanisms of action, symptoms and health outcomes associated with perimenopause remains 
characterized by poor methodology and inconsistent terminology. This hinders our understanding of the complexities inherent in this important process in a woman's lifespan. Thus far, the menopausal transition has been examined primarily through the lens of a biomedical model. The focus has been on the associated hormonal fluctuations and potential pharmacological interventions such as hormone replacement therapy (HRT) with relatively little research targeting psychological and social aspects of this important developmental milestone. In fact, examination of the literature on the menopausal transition reveals a ratio of approximately 60 to 1 of articles in medically-oriented journals versus those in psychology-oriented journals - a substantially greater ratio than those for other significant milestones in the human female reproductive lifespan, childbirth (17 to 1) and pregnancy (16 to 1; Rubinstein, 2013).

Centrality of the body. Given the unique nature of the menopausal transition, it is important to further our understanding of body image and the role of a compassionate stance toward this important stage in a woman's lifespan. Due to the centrality of the body to the experience of perimenopause, body compassion-a construct capturing the relationship with one's body or physical self (Altman et al., 2017)—would be expected to be a significant factor in this time period. Furthermore, the level of compassion with which a woman relates to and engages with her own experience of this important transition would be expected to impact psychological and physical outcomes. As hormones shift and effect physical changes in a woman's body throughout perimenopause, her attitudes, cognitions and internal dialogue about her body have the potential to shift, or to become more firmly entrenched, particularly if she has a history of negative views of her own body. Hypothetically, body compassion is an attribute that 
may be cultivated, much like self-compassion, and applied in situations that threaten one's sense of physical integrity. For example, developing body compassion during the perimenopausal transition is hypothesized to help normalize the experience by reducing distress associated with characteristic symptoms, and in doing so improving associated health outcomes.

Medicalization of perimenopause. Perimenopause is a natural phase of a woman's life. Predictable changes occur in the body and have been defined medically. Another way to view perimenopause is through the lens of how a woman relates to her own body, and to encourage the adoption of a compassionate approach. This paper will review a number of the physical changes of perimenopause that have been medicalized, a stance which pulls a woman away from her own experience of her body. It is important to note that standard terminology used in the literature regarding the perimenopausal experience - terms such as 'symptom'-inherently pathologize this natural phase of life. This language is reflective of deeply entrenched cultural values in the United States and much of the western world, values which seek to prolong youth, staving off the inevitability of aging and death. Applying mindfulness- and acceptance-based (MAB) concepts, such as body compassion, requires a shift in view to a recognition, and perhaps even celebration, of the natural processes of life and awareness of where one is in the cycle. Given the current state of the literature, and the extent of review in this paper, this paper will primarily employ language consistent with the existing literature, with shifts in terminology as available, such as using 'characteristics' in place of 'symptoms.'

Defining the Menopausal Transition. Menopause may take place naturally (the permanent cessation of menstruation, recognized after 12 consecutive months without 
menstruation with no obvious cause), as the result of medical treatment (e.g., chemotherapy), or as the result of surgery (e.g., hysterectomy) (World Health Organization (WHO), 1996). The menopausal transition has been described as the manifestation of reproductive aging which occurs at midlife and is marked by "midlife menstrual irregularity culminating in a final menstrual period" (Smith-DiJulio, Woods, \& Mitchell, 2008, p. 310). Considered the gold standard for describing the menopausal transition, each of the stages have been defined by the Stages of Reproductive Aging Workshop +10 (STRAW +10; Harlow et al., 2012).

For ease of reference in examining the literature and focusing on the population of interest, the stages of STRAW +10 will be collapsed into three sequential stages. First is premenopause, which is the late reproductive stage referring to "the time before persistent menstrual cycle irregularity begins during midlife." Second is perimenopause, which is "marked by persistent irregularity with greater than or equal to 7 days' difference between any 2 consecutive menstrual cycles, without skipping periods" and "persistent skipping of menstrual periods, resulting in greater than or equal to 60 days of amenorrhea." Finally is postmenopause, which begins with "the first 5 years after the final menstrual period" (Smith-DiJulio et al., 2008, p. 311).

Health Outcomes. For many women who are asymptomatic, the menopausal transition is viewed as largely unremarkable and is regularly associated with positive outcomes (Busch, Barth-Olfsson, Rosenhagen, \& Collins, 2003). However, for those women who are symptomatic, the menopausal transition may represent a time of many potentially deleterious effects on their quality of life and health, including an array of symptoms initiated by a shifting hormonal environment, increased risk of osteoporosis, 
increased risk of cardiovascular disease and lower subjective well-being (Pearce et al., 2014; Soares et al., 2005). Evidence suggests that beyond the degree of symptoms experienced, the menopausal transition directly physically impacts significant health risks of women in midlife, particularly in cardiovascular disease and stroke (Abernethy, 2008; Lisabeth et al., 2009; Newhart, 2013).

Hormone replacement therapy. HRT is a medical intervention for symptomatology of the menopausal transition that has evidence suggesting it offers relief of symptoms, improves quality of life and may reduce the likelihood of osteoporosis and cardiovascular disease (Schneider, 2013). Simultaneously, potential risks of HRT that have been identified include endometrial hyperplasia, multiple cancers, gall bladder diseases and venous thromboembolic events (Schneider, 2013; Shapiro, 2013; USDHHS, 2013). Given the mixed evidence in support of and against its use in intervention, HRT remains a controversial treatment option for symptoms of the menopausal transition.

Symptoms. The symptoms consistently associated with the menopausal transition occur most frequently and with the greatest severity during perimenopause. They include: vasomotor symptoms (hot flashes and night sweats), vaginal dryness, sleep disturbance, depression, anxiety, cognitive symptoms (e.g., memory loss), sexual difficulties, fatigue, joint pains, headache, and weight gain (Mishra \& Kuh, 2012; O’Bryant, Palay, \& McCaffrey, 2003; Pearce et al., 2014; Woods \& Mitchell, 2005).

Reported rates of symptomatology associated with perimenopause are mixed, however, there does seem to be consensus on the symptoms for which women most often seek health care: vasomotor symptoms, sleep disturbances, bleeding, and depressed mood 
(Woods \& Mitchell, 2005). The areas of focus for the remainder of this paper will be vasomotor symptoms, sleep disturbance, and depressive symptoms.

Vasomotor symptoms. Vasomotor symptoms include hot flashes and night sweats, most commonly referred to in the literature as hot flashes (United States) or hot flushes. Night sweats are hot flashes that occur at night. While night sweats have been examined independent of hot flashes (Ayers, Smith, Hellier, Mann, \& Hunter, 2012), they are typically studied and referred to together as vasomotor symptoms, HFNS, or simply as hot flashes. For ease of reporting and to stay in line with the bulk of the literature, in this paper the primary terms used will be hot flashes or vasomotor symptoms.

"Hot flashes are commonly defined as transient periods of intense heat in the upper body, arms, and face, which are often followed by flushing of the skin and profuse sweating" (Whiteman, Staropoli, Benedict, Borgeest, \& Flaws, 2003, p. 459). Hot flashes have distinct physiological characteristics compared with other flushing conditions, including: increased peripheral blood flow, increased heart rate, and a decrease in galvanic skin resistance (Sturdee, 2008). Many factors involved in hot flashes have been identified, including: estrogen, estrogen antagonists (tamoxifen and raloxifene), lutenising hormone, and chemical pathways (involving serotonin, noradrenalin and dopamine), among others (Sturdee, 2008). It is thought that hot flashes are caused by a disruption of the temperature regulating mechanism in the hypothalamus; however, the precise mechanisms remain a mystery (Sturdee, 2008).

Hot flashes are considered the hallmark symptom of the menopausal transition and are often experienced as distressing (Sturdee, 2008). In the United States they are the most commonly reported symptom of perimenopause, and the principal cause of women 
in the menopausal transition seeking medical treatment. Various studies have reported anywhere from $45 \%$ to $80 \%$ of perimenopausal women as experiencing hot flashes (Gallicchio et al., 2015; Morrow, Mattair \& Hortobagyi, 2011; Thurston \& Joffe, 2011). Yet despite their prevalence and the associated reduced quality of life of a large segment of women in perimenopause, clinical and research interest has been limited. Perhaps because hot flashes are not considered life threatening or especially harmful, understanding the pathophysiology of hot flashes has not been prioritized (Sturdee, 2008). However, vasomotor symptoms have been implicated in sleep disturbance, depressed mood, and trait anxiety in perimenopausal women (Kloss, Tweedy, \& Gilrain, 2004).

Potential risk factors for hot flashes include depressive symptoms, history of oral contraceptive use, smoking, hormone levels, BMI, surgical menopause, tubal ligation, and race/ethnicity (Gallicchio et al., 2015; Whiteman et al., 2003). There is especially compelling epidemiological evidence implicating smoking as a contributory factor (Whiteman et al., 2003). African American women may report more vasomotor symptoms than Caucasian women (Kloss et al., 2004), although implications of race and the remaining potential risk factors require further research (Whiteman et al., 2003).

How women relate to the experience of hot flashes has also been explored. In an examination of relationships between perceived control, coping strategies and hot flashes, women who felt low control reported more frequent hot flashes; and it is not necessarily the coping behavior itself that differentiates between women with varying levels of distress, rather it is the attitude of the women towards the coping behaviors (Reynolds, 1999). For example, the coping strategy used in response to hot flashes, such as wearing 
certain fabrics or opening a window, in itself caused distress among some women due to a shift in their body image, particularly by feeling "frumpy" or different from the premenopausal self (Reynolds, 1999, p. 30). Relating to the physical changes of perimenopause with a body image attitude of critical evaluation may negatively impact outcomes of symptom expression and related distress, exacerbating other characteristics of perimenopause, such as sleep disturbance.

Sleep disturbance. The average adult prevalence of reported sleep disturbance is $30-35 \%$ (Kloss et al., 2004). In general, sleep disturbance is reported more often by women than men, with $25 \%$ of women between the ages of 50 and 64 reporting insomnia and $15 \%$ reporting severe insomnia, with reports of insomnia in 51 to $77 \%$ of perimenopausal women (Kloss et al., 2004; Polo-Kantola et al., 2001; Shaver \& Zenk, 2000). However, sufficient data linking sleep disturbances to the menopausal transition are not available — given the literature, either menopausal transition causes sleep disturbances or they just coincide (Kloss et al., 2004; Polo-Kantola et al., 2001; Shaver \& Zenk, 2000).

Sleep disturbance includes both subjective and objective reports. The subjective reports include difficulty falling asleep, frequent awakening throughout the night, awakening too early in the morning, and nonrestorative sleep. The objective reports include sleep architecture abnormalities or inefficiencies available via measurement with all-night polygraphic recording (Polo-Kantola et al., 2001). Clinically, sleep disturbance associated with perimenopause is not distinct from common sleep disturbances. Sleep disturbance in perimenopause may be primary or secondary to other symptoms of perimenopause, such as vasomotor events or depression (Kravitz et al., 2008; Polo- 
Kantola et al., 2001; Sharkey et al., 2003; Shaver \& Zenk, 2000). The difficulty in differentiating between sleep disturbance due to other symptoms of perimenopause presents a challenge in determining the most appropriate intervention.

Findings on use of HRT for sleep disturbances in perimenopause have been mixed, showing no difference in sleep quality between perimenopausal women taking HRT and those not taking HRT (Kloss et al., 2004); and in other studies HRT has been identified as an effective treatment for subjective reports of sleep disturbances in perimenopause. However, the sleep quality of perimenopausal women, both with and without vasomotor symptoms, benefits from estrogen, leaving in question the predictive ability of the association of vasomotor symptoms and sleep disturbance (Polo-Kantola et al., 2001). Furthermore, there are conflicting reports on the effectiveness of HRT on objective reports of sleep architecture and efficiency (Polo-Kantola et al., 2001). There is a relatively complex association between sleep, vasomotor and depressive symptomsand HRT appears to be important to those points of intersection.

Depressive symptoms. The menopausal transition is a time of vulnerability to depressive symptoms, specifically as a response to hormonal changes, independent of demographic, psychosocial, behavioral and health factors. However, the evidence is not conclusive that depressive disorders occur more commonly during the menopausal transition (Judd, Hickey, \& Bryant, 2012). The prevalence of depressive symptoms among perimenopausal and postmenopausal women combined has been reported as high as $42 \%$ (Green, Key, \& McCabe, 2015; Timur \& Sahin, 2010). Overall, it has been reported that there is a slight increase in minor psychological symptoms during 
perimenopause, following which prevalence rates of depression fall postmenopause (Robinson, 2001).

There are a variety of hypotheses regarding the occurrence of depression and depressive symptomatology in perimenopausal women, including: the influence of negative attitudes and expectations of the menopausal transition; the subjective experience of and reactions to the physical experience of perimenopause; a heightened sensitivity to the neuroendocrine effects of hormonal changes; and the increased frequency of changing relationships due to significant life events during this stage of life, such as death of a parent or a child moving away from home for the first time (Rasgon et al., 2005; Robinson, 2001).

It is a common perception that depression and perimenopause are linked; however, the literature is not consistent regarding a potential association between the menopausal transition and depression (Avis, 2003; Burt, Altschuler, \& Rasgon, 1998; Soares et al., 2005). There is evidence that upon entering perimenopause, women with no lifetime history of major depression are twice as likely to develop significant depressive symptoms as are women who remain premenopausal, and that this increased risk is somewhat greater in women who report vasomotor symptoms (Cohen, Soares, Vitonis, Otto, \& Harlow, 2006). It has also been reported that compared with those in premenopause, women in perimenopause are three times as likely to report depressive symptoms and that an increase in hormone levels and their variability is associated with this increase in depressive symptoms (Freeman et al., 2006). Given the current literature, no clear conclusion can be drawn regarding causal factors of depression in 
perimenopause (Llaneza, García-Portilla, Llaneza-Suárez, Armott, \& Pérez-López, 2012).

The menopausal transition typically occurs during the time of numerous psychosocial changes in a woman's life as well, such as changing family dynamics with parents, children and intimate relationships. A portion of women going through the menopausal transition may be more vulnerable to associated hormonal changes, predisposing them to the onset of depression (Avis, 2003). Moreover, the report of depressive symptoms among perimenopausal women has been reported to be two times higher among those with a body mass index (BMI) of $25 \mathrm{~kg} / \mathrm{m}^{2}$ or higher than of those with a BMI less than $25 \mathrm{~kg} / \mathrm{m}^{2}$ (Timur \& Sahin, 2010). Other factors found to be associated with depressive symptoms during the menopausal transition are history of depression, recent negative life events, and severity of the somatic symptoms of perimenopause, with aerobic exercise potentially playing a protective role (Gibbs, Lee, \& Kulkarni, 2013). Overall, perimenopause presents a time of greater susceptibility to depressive symptoms, possibly due to the interaction of hormonal fluctuations with an individual's psychosocial resources, overall well-being (including exercise and other health behaviors) and stressful life events (Gibbs et al., 2012; Rasgon et al., 2005). Health outcomes associated with higher levels of depressive symptoms include an increase in cardiovascular risk, as well as poorer cognitive function and sexual functioning (Llaneza et al., 2012; Soares et al., 2005).

The shifting hormones of perimenopause impact depressive symptoms, sleep disturbance and vasomotor symptoms, which in turn each impact each other and are a 
few key manifestations of the changing body. The physical changes that happen during perimenopause inevitably impact the image women have of their bodies.

Body Image in Perimenopausal Women. Rates of body dissatisfaction appear to be relatively consistent across the lifespan, not decreasing among women until ages 75 and older, yet the bulk of the research on body image has focused on younger women, approximately ages 18-29 (Tiggemann, 2011). This is likely due in part to three key factors: 1) the link between poor body image and eating disordered behaviors known to be prevalent in younger women, 2) the convenience of sampling from college populations, and 3) it may be a manifestation of the cultural value placed on youth and reproductive status. Yet, the finding that rates of body dissatisfaction in women remain consistent from age 18 to at least age 75 suggests the potential for comparable levels of distress in years beyond 18-29. This distress may have varying cognitive and behavioral manifestations as women age, particularly during the ever changing milieu of the perimenopausal body.

There is limited research on body image and the menopausal transition, and no study published to date that examines body image specifically in perimenopausal women. In a review of the previous 20 years of research on body image and the menopausal transition, Pearce and colleagues (2014) identified only 15 studies meeting criteria, seven of which were qualitative in nature-relying solely on interview data, seven were quantitative - utilizing self-report questionnaire data, and one study was mixed methods. None of the studies examined interventions for body image specific to women in the menopausal transition. The authors highlighted the prevalence of exploratory-based studies and the need for further research with the aim of developing interventions for 
coping and self-management throughout the menopausal transition. Pearce and colleagues (2014) also highlighted the complexity of the menopausal transition and the importance of not oversimplifying it into a dichotomous positive or negative experience.

In a study of body dissatisfaction and self-image across the life span examining relevant variables in women ages $20-65$ years, body dissatisfaction and body importance did not differ across age groups. However, the strength of the relationship between body dissatisfaction and self-concept and self-esteem was reduced with increasing age and increasing perceptions of cognitive control. Based on this result, the authors suggest "that the cognitive strategies of older women protect their self-concept and self-esteem from the influence of body dissatisfaction" (Webster \& Tiggemann, 2003; p. 241). In this study “older women" were 50-65 years old, and are likely peri- or postmenopausal, and in both studies as women age they may be adaptively shifting their cognitions in response to physical changes.

The evidence is mixed regarding the presence of negative body image in women who are likely peri- or postmenopausal. While body dissatisfaction and body shame remain stable across the life span, research suggests that appearance-related anxiety is negatively correlated with age and that body dissatisfaction does not correlate with selfesteem in women as they age beyond 40 years (Tiggemann \& Lynch, 2001; Webster \& Tiggemann, 2003). Some have suggested that the data point to a persistence of body dissatisfaction across the lifespan, but a lessening of negative impact as women age (Pruis \& Janowsky, 2010), perhaps owing to the body becoming less important as one ages (Tiggemann \& Lynch, 2001). However, a review of research based on major databases (e.g. PubMed) reveals a dearth of literature specifically examining the 
processes and outcomes of body image and related constructs, positive or negative, in women who are likely peri- or postmenopausal, so it remains difficult to draw any conclusions. In particular, the research on body image in women as they age often does not account for the influence and experience of the menopausal transition.

All of the characteristics of perimenopause impact women's relationships with their body because it is a developmental change - a fundamental alteration in women's experience of, and with, their bodies. The shifting nature of the body in perimenopause influences one's relationship to the body. The unique challenges and opportunities present during this transition would benefit from a compassionate stance toward the body and this natural progression through the cycle of a woman's life. HRT is the predominant intervention available to women in perimenopause and at best only manages the occurrence of characteristics/symptoms of perimenopause, not the impact of those characteristics and how they are experienced based on a woman's view of, and relationship with, her body.

Self-Compassion in Perimenopausal Women. In a review of the literature only two studies (by the same research group) have directly examined the role of selfcompassion in the menopausal transition, and both focus on vasomotor symptoms as the primary indicator of the menopausal experience (Brown, Bryant, Brown, Bei, \& Judd, 2014, 2015). Using path analysis, Brown et al. (2014) explored self-compassion as a moderator of the relationship between hot flush and night sweat (HFNS) frequency and hot flush interference (HFI) in daily activities, and the resulting influence of HFI on depressive symptoms. They found that self-compassion did moderate the relationship between HFNS frequency and HFI, and that it also had a direct influence on ratings of 
HFI and on reported symptoms of depression. Utilizing structural equation modeling, Brown et al. (2015) further explored the moderation by self-compassion of the relationship between HFNS frequency and HFI. The resulting influence of HFI was examined not only on depressive symptoms, but also on hedonic and eudaimonic wellbeing. Also accounted for were menopausal beliefs regarding identity, consequences, time frame and perceptions of control as measured by the Menopause Representation Questionnaire (MRQ; Brown, 2015; Hunter \& O’Dea, 2001). In the resulting model, selfcompassion was significantly related to outcomes, accounting for two to ten percent unique variance above HFNS, MRQ scores and demographics (Brown et al., 2015).

The findings of these two studies highlight the emphasis of a compassionate stance, in this case self-compassion, not on management or manipulation of symptoms, but rather on having a stance of increased awareness and acceptance of experience. For example, in the path analysis, Brown et al. (2014) found that self-compassion lessened the strength of the relationship between HFNS frequency and interference in daily life and depressive symptoms. This suggests that higher levels of self-compassion may influence the experience of HFNS in a manner that reduces distress (i.e., interference and depressive symptoms), rather than attempting to directly reduce the occurrence of HFNS.

Notably, self-compassion is a construct referencing the general or overall self and it has been used in numerous studies examining a variety of facets of the human experience. However, it is possible that the more nuanced elements of particular experiences - such as the very physical, body-centered experiences of perimenopauseare not being adequately captured and subsequently addressed. Hence the importance of 
investigating a shift from the general view of self-compassion to a more precise focus on body compassion.

\section{Summary}

The BCS was designed for use in research, clinical assessment and intervention regarding the role of body compassion in understanding, preventing, and enhancing health promoting behaviors, psychological wellbeing and/or quality of life. In its development thus far, a three factor solution of the BCS has been identified and confirmed in two distinct samples of undergraduates. Perimenopause is a key developmental period in a woman's life which presents an ever-changing milieu of physical manifestations of shifting hormones and an aging body. However, the research on perimenopause - its symptoms and health outcomes - and the way women relate to their bodies and to their experience of their bodies during this time, is lacking, both in research and clinical applications. Body compassion presents an opportunity to directly measure and ultimately intervene with the experience of perimenopause. Given the significance of the body in the experience of perimenopause, women in perimenopause are an ideal population for cross-validation of the BCS.

\section{Purpose of the Present Study}

The present study is a cross-validation of the BCS in a sample of women in perimenopause - the next step in the scale development process (See Figure 1, h). Despite the centrality of the body in the experience of the menopausal transition, there is remarkably little research on body image and perimenopause; and only three studies report on the role of self-compassion and/or mindfulness in the menopausal transitionnone with any examination of body image related issues (Brown et al., 2014; Brown et 
al., 2015; Carmody et al., 2011). As treatment paradigms shift from a goal of manipulating the content or nature of thoughts to a stance of increased awareness and acceptance of thoughts, new ways of conceptualizing constructs related to mindfulness and acceptance are emerging. Therefore, it is important that corresponding assessment, and valid and reliable tools of measurement be developed and evaluated (Baer, Smith, Hopkins, Krietemeyer, \& Toney, 2006; Smolak \& Cash, 2011). Herein lies an opportunity for cross-validation of the BCS in a variety of populations, including women in perimenopause. Exploring the overlap of self-compassion specific to body imagerelated experiences via body compassion may provide an assessment that more accurately captures and addresses the experience of relating to one's body. The present study examines the factor structure of the BCS in a sample of women in perimenopause. 


\section{CHAPTER II}

\section{METHODS}

\section{Participants}

Participants in this study were women in perimenopause recruited via Amazon's Mechanical Turk (Mturk) service (www.mturk.com). Participants were compensated US $\$ 1.00$ for each completed online packet. This rate of incentive is consistent with other social science studies and projects in which data were collected via MTurk (Casler, Bickel, \& Hackett, 2013). Mturk was designed in 2005 as an online "marketplace" that pairs "requesters" with "workers" for short-term tasks that require human intelligence. Requesters (i.e., researchers) seek workers (i.e., participants) to perform Human Intelligence Tasks (HITS) that last at least one minute in duration. Workers, in turn, receive nominal compensation through Amazon when a HIT is complete. Social and behavioral science researchers have begun to utilize Mturk as a resource for data collection that supersedes efficiency of previous methodologies such as online groups through platforms such as Yahoo! Or Facebook (Buhrmester, Kwang, \& Gosling, 2011). Buhrmester and colleagues (2011) note that demographic characteristics of Mturk participants are "at least as diverse and more representative of noncollege populations than those of typical Internet and traditional samples" (p.5) and thus, may enhance generalizability of research findings (Rouse, 2015). Moreover, recent studies of Mturk samples also suggest that the psychometric quality of data collected through Mturk met or exceeded the psychometric standards inherent to published studies in traditionally 
recruited samples. Finally, Rouse (2014) found that when affirmation of attentiveness items (e.g., "This item is to be sure you are paying attention as you respond. If you have just read this, choose ' 5 '.") were included in lengthier study surveys, the reliability of scores was greater than reliability of scores obtained when such checks were not employed. Inclusion criteria were: Participants must be able to independently provide informed consent, be able to read and respond in English, and must be in perimenopause as determined by a positive response to the screening question, "Are you currently experiencing persistent irregularity with 7 or more days' difference between any 2 consecutive menstrual cycles, without skipping periods? Or are you currently experiencing the persistent skipping of menstrual periods, resulting in 60 or more days' without having a period?" Exclusion criteria include: mental or physical disability/impairment preventing completion of self-report measures online.

The recommended number of participants needed for a confirmatory factor analysis ranges from a minimum of 3 participants per scale item to 10 participants for each item with no fewer than 100 participants (Bollen, 1989; Gorsuch, 1983). Therefore, to ensure adequate power the aim was to have 10 participants per item. Given 23 items the number of participants needed was 230 (Gorsuch, 1983), so the aim was to recruit at least 300 participants and 281 total participants were included in analyses. See Figure 3 of recruitment and accrual rate. 




Figure 3. Participant recruitment and accrual.

\section{Procedures}

Participants completed self-report questionnaires online through Qualtrics. The study survey website contained a description of the study, procedures and preamble informed consent. The introductory page was followed by the collection of self-report questionnaires and a concluding page, which thanked participants. Consistent with IRB protocol, contact information and phone numbers were provided to enable survey respondents to contact the study investigator if they had questions or concerns about their study participation. One survey respondent made contact by emailing through the MTurk website to clarify her health-related responses to ensure we had accurate data.

Measures. The selected measures provided data for cross-validation of the BCS in a sample of women in perimenopause. To do this, the data were examined to evaluate 
1) the BCS factor structure with SEM, and 2) the association of several other measures to provide concurrent validity.

\section{General and Medical Background Measures}

General Demographics and Medical History Questionnaire. Each participant will be asked to complete a brief demographic questionnaire assessing age, race, ethnicity, religious affiliation, education, income level, occupation, relationship status, number of children, and number of individuals in the household.

Body Mass Index (BMI). BMI is a statistical measure calculated by comparing the relationship between an individual's height and weight. It is oftentimes used to estimate an individual's relative weight compared to his/her height and ranges from

"underweight" (BMI < 18.5) to "obese" (BMI > 30).

\section{Measures of Symptoms/Characteristics of Perimenopause}

Menopause Rating Scale (MRS; Potthoff, Heinemann, Schneider, Rosemeier, \& Hauser, 2000). The Menopause Rating Scale is comprised of 11 items that represent common symptoms of menopause. Respondents are asked to rate symptoms on a $0=$ none to 4 = very severe scale. The MRS contains three dimensions/subscales of symptoms: psychological symptoms (depressed, irritable, anxious, and exhausted), somato-vegetative symptoms (sweating/flush, cardiac complaints, sleeping disorders, joint and muscle complaints), and urogenital symptoms (sexual problems, urinary complaints, and vaginal dryness). The total score ranges from 0 (asymptomatic) to 44 (highest degree of complaints). Scores can also be broken down by severity from "no/little complaints" (total score of 0 to 4$)$ to "mild" (5 to 8) to "moderate" (9 to 15$)$ to 
"severe" (16 or more points). Across multinational studies internal consistency and testretest reliability have been found to be good (Heinemann, Ruebig, et al., 2004).

Pittsburgh Sleep Quality Index (PSQI; Buysse et al., 1989). The Pittsburgh Sleep Quality Index is a self-report measure comprised of 18 items and the following subscales: duration of sleep, sleep disturbance, sleep latency, daytime dysfunction due to sleepiness, sleep efficiency, overall sleep quality, and use of medications. Respondents rate the frequency of certain sleep problems from "not during the past month" to "three or more times a week." Internal consistency ranges from $\alpha=0.77$ to $\alpha=0.83$. Test-retest reliability of the PSQI is adequate $(r=.85)$.

Center for Epidemiological Studies-Depression Scale (CES-D; Radloff, 1977).

The CES-D scale is a widely used, short (20-item) self-report scale that was originally designed to measure depressive symptomatology in the general population (Radloff, 1977). The scale items of the scale are symptoms associated with depression which have been used in previously validated longer scales. The four-factor structure of the CES-D includes factors: Depressed Affect (DA; 7 items), (lack of) Positive Affect (PA; 4 items), Somatic Symptoms and Retarded Activity (SS; 7 items), and Interpersonal Difficulties (ID; 2 items). Respondents are asked to indicate the frequency of each feeling or behavior on a scale of 0 (rarely or none of the time) to 3 (most or all of the time) over the past 7 days. The four positive affect items are reverse scored. Higher scale scores indicate more severe depressive symptoms. The factor structure of the measure has been replicated and the measure used across a variety of community and clinical/medical populations with acceptable-to-excellent internal consistencies (Gomez \& McLaren, 2015; Edwards, Cheavens, Heiy, \& Cukrowicz, 2010). Although the four factor model has been widely 
replicated, the CES-D is commonly scored as one total score by summing all items. The factor structure and use of single total score has been examined extensively by Edwards et al. (2010). They concluded that the four PA items are measuring a construct other than depression and have recommended that if a single score is used, that the 4 positively worded items from the PA scale be omitted and that only remaining 16 items be used to create a single depression score. Accordingly, the 16-item total score (omitting 4 PA items) will be utilized in final analyses.

Hot Flash Related Daily Interference Scale (HFRDIS; Carpenter, 2001). Hot Flash Related Daily Interference Scale (HFRDIS). A 10-item measure assessing the degree to which vasomotor symptoms interfere with nine daily activities, including: work, socializing, leisure, sleep, mood, concentration, relaxation, sex and enjoyment of life. Notably, the tenth item measures the degree hot flashes interfere with overall quality of life. The HFRDIS was developed to include daily life activities specific to the impact of hot flashes (Carpenter, 2012). Respondents are asked to "describe how much DURING THE PAST WEEK hot flashes have INTERFERED with each aspect of your life" using a 0 (do not interfere) to 10 (completely interfere) point scale. The measure is a single factor scale with a score computed by summing items with a possible range of 0 to100. Higher scores indicate higher life interference due to hot flashes. Internal consistency for the measure are good-to-excellent with Cronbachs alphas of the HFRDIS ranging from 0.91 to 0.96 (Carpenter, 2001; Carpenter, Guthrie, Larson, Freeman, Joffe, Reed, Ensrud \& LaCroix, 2012). 


\section{Body Image, Mindfulness and Acceptance-Based Measures}

Body Compassion Scale (BCS; Altman et al., 2015). A 23-item measure consisting of a total score and three subscales (Defusion, Common Humanity, and Acceptance).

Five Facet Mindfulness Questionnaire (FFMQ; Baer, Smith, Hopkins \& Krietemeyer, \& Toney, 2006). The FFMQ is a 39-item measure designed to measure five different facets of mindfulness. These facets include observing, describing, acting with awareness, non-judging of inner experience, and non-reactivity to inner experience. Items are rated on a scale from 1 ("never or rarely true") to 5 ("very often or always true") for statements such as "I'm good at finding words to describe my feelings," and "When I do things, my mind wanders off and I'm easily distracted." Internal consistency for facets ranged from $\alpha=0.72$ to $\alpha=0.92$, except non-reactivity with $\alpha=0.67$ (Baer et al., 2006).

Self-Compassion Scale (SCS; Neff, 2003b). The SCS is a 26-item measure used to assess a total self-compassion score and subscale scores for common humanity (4 items), isolation, self-kindness (5 items), self-judgment (5 items), mindfulness (4 items), and over-identification (4 items). Respondents are asked to "indicate how often [they] act in the manner stated" in each of the items on a 5 -point scale from $1=$ Almost Never to $5=$ Almost Always. Items representing negative or "uncompassionate" responses are reversecoded such that higher scores are positive or indicative of higher levels of selfcompassion. A total score may be calculated to indicate overall self-compassion. The now widely used SCS, has demonstrated good-to-excellent internal consistencies and test-retest reliabilities (Neff, 2003b, 2016). 


\section{Multidimensional Body-Self Relations Questionnaire - Appearance Scales}

(MBSRQ - AS; Brown, Cash \& Mikulka, 1990). The MBSRQ-AS is a 34-item scale derived from the longer 69 item scale. Includes the following subscales: Appearance Evaluation, Appearance Orientation, Overweight Preoccupation, Self-Classified Weight, and the Body Areas Satisfaction Scale. The MBSRQ-AS is widely used in research as well as clinical application. Respondents are asked indicate the extent to which each statement pertains to $[$ them $]$ personally" on a 5 point $(1=$ Definitely disagree to $5=$ Definitely agree) scale. Items types on the Appearance Subscale include "I am very conscious of even small changes in my weight" and "It is important that I always look good." Although a total score may be derived, authors recommend that scores are summed within each subscale (Cash, 2000). Among women in the normative sample, internal consistencies on scales range from good (0.78) to excellent (0.94) (Brown, Cash \& Mikulka, 1990).

Body Image-Acceptance and Action Questionnaire (BI-AAQ; Sandoz, Wilson, Merwin, \& Kellum, 2013). The BI-AAQ is a 12-item measure assessing an individual's Body Image Flexibility (Sandoz et al., 2013). It was developed from previously established psychological flexibility questionnaires (Bond, Hayes, Baer, Carpenter, Guenole, Orcutt, Waltz \& Zettle, 2011) and adapted to assess body-related thoughts and feelings. Respondents are asked to rate how applicable each statement is on a 7-point Likert scale ranging from 1 ("Never True") to 7 ("Always True"). The BI-AAQ produces a unidimensional score by reverse scoring and summing all items. Higher scores indicate a greater degree of Body Image Flexibility. Sandoz et al. (2013) established reliability and validity for the BI-AAQ from three samples of college-aged students $(\mathrm{N}=704)$. 
Overall internal consistency for the BI-AAQ was a Cronbachs $\alpha=0.93$ and good testretest reliability of 0.8 .

Body Appreciation Scale - 2 (BAS-2; Tylka \& Barcalow, 2015). The original BAS was conceptualized as a positive body image measure in an effort to deviate from the tradition of a more negative tenor of body image research. The 13-item BAS scale (Avalos, Tylka, \& Wood-Barcalow, 2005) has been further examined and refined to a 10 item scale that assesses “individuals' acceptance of, favorable opinions toward, and respect for their bodies" (Tylka \& Barcalow, 2015, p. 53). Respondents are asked to indicate whether an item is "true about [them] never, seldom, sometimes, often or always." The scale is unidimensional (i.e., a one factor solution), therefore a single total score is calculated by summing the scale items. Higher scores indicated higher levels of body appreciation. Internal consistency of the measure was excellent for each of the four BAS-2 normative samples (Cronbachs alpha $=0.96$ for each group).

Methods for Data Quality Control. To control for potential errors in answering the questionnaires online (i.e. careless or nonsensical responding) three items were randomly distributed throughout the questionnaire stating, "This item is to be sure you are paying attention as you respond. If you have just read this, choose ' 5 '.' 


\section{CHAPTER III}

\section{RESULTS}

This chapter reviews the findings of the confirmatory factor analysis (CFA) and concurrent validity of the BCS, as well as supplementary and exploratory analyses. Supplementary analyses assessed a second-order CFA, as well as examining relationships among the variables specific to women in perimenopause. Exploratory analyses were also conducted to examine questions pertaining to future directions in the validation of the BCS and the application of body compassion.

\section{Sample description}

Data from a total of 281 women in perimenopause (mean age $=42.92$ years, standard deviation $(\mathrm{SD})=9.71)$ were included in analysis (see Figure 3 of recruitment and accrual rate). The sample was $83.6 \%$ White, $10 \%$ Black, 5.3\% Hispanic, $3.2 \%$ American Indian/Alaska Native, 1.8\% Asian, and 1.8\% selected 'Other,' and specified being 'mixed,' 'more than two races,' and 'European/American.' The average Body Mass Index $(\mathrm{BMI})$ was $28.30(\mathrm{SD}=7.36)$.

The sample lived in varied geographical locations across the United States (See Figure 4) with $29.6 \%$ living in urban areas, $52.5 \%$ suburban, and $17.9 \%$ rural. Participants lived in forty-six states and Puerto Rico, with the highest response rates in Texas $(n=22)$, Florida $(n=18)$, North Carolina $(n=17)$, Pennsylvania $(n=17)$, California $(n=14)$, Michigan $(n=14)$, Georgia $(n=13)$, Virginia $(n=11)$, and New York 
$(\mathrm{n}=11)$. The majority of the sample $(69.4 \%)$ was married or living with a partner and $71.1 \%$ had children living at home. See Table 8.

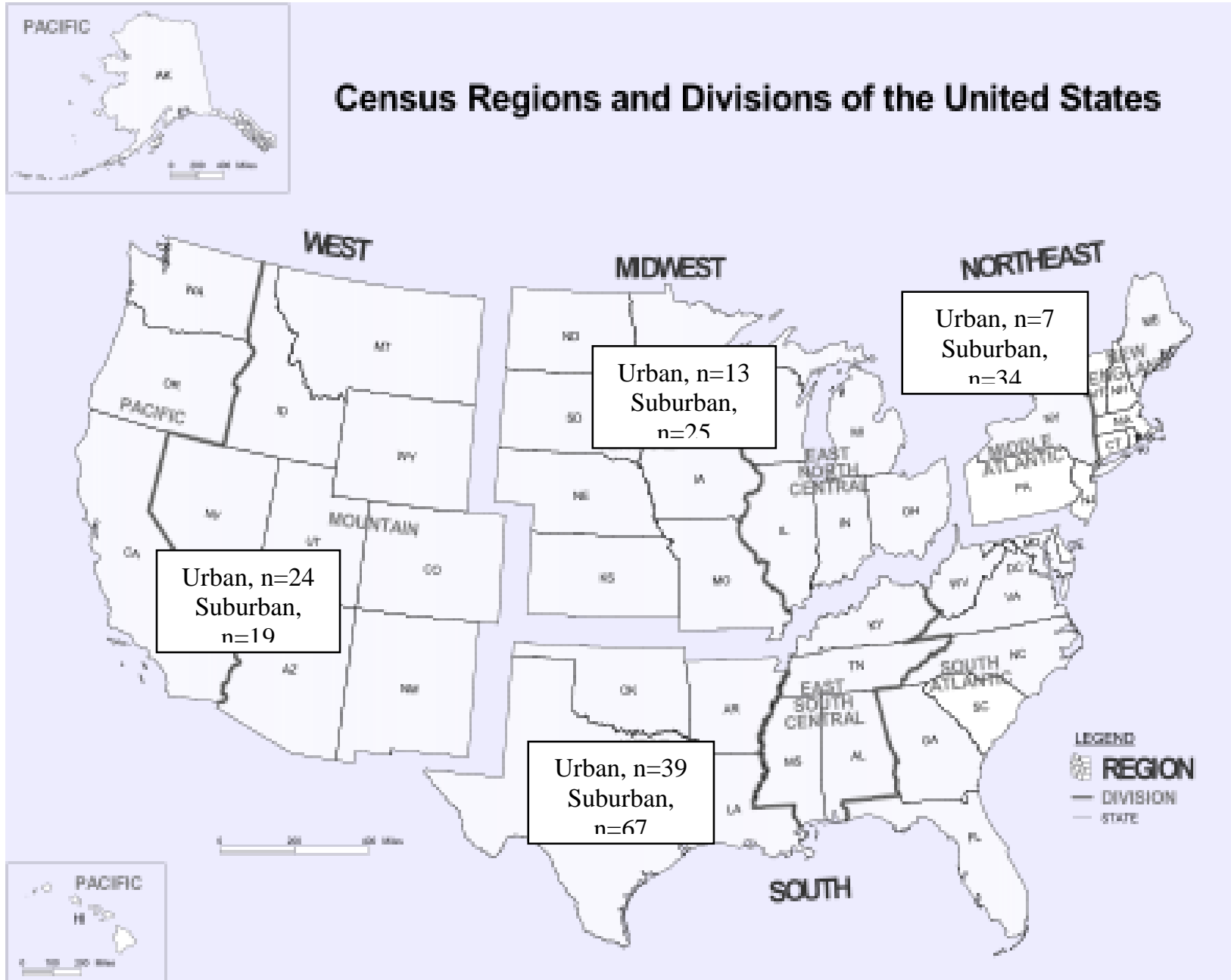

Figure 4. Participant locations by U.S. Census Bureau regions (2017). *Does not include one participant in a suburban location with unknown region and one participant in a rural location 
Table 8.

\begin{tabular}{lllllll}
\hline \multicolumn{1}{c}{$\begin{array}{c}\text { Marital/Partner } \\
\text { Status }\end{array}$} & \multicolumn{5}{c}{ Number of children living at home } \\
\cline { 2 - 6 } & 0 & 1 & 2 & 3 & 4 & $5+$ \\
\hline Single & 12 & 1 & 3 & 1 & 1 & 0 \\
Married & 30 & 43 & 39 & 23 & 6 & 1 \\
Living with partner & 13 & 8 & 3 & 1 & 0 & 0 \\
Divorced & 8 & 9 & 9 & 4 & 1 & 0 \\
Separated & 1 & 3 & 0 & 0 & 1 & 1 \\
Widowed & 2 & 1 & 2 & 0 & 1 & 0 \\
\hline
\end{tabular}

Description of marital/partner status and number of children living at home.

Most of the sample (69.4\%) were employed, with $37.7 \%$ working fewer than 40 hours per week and $31.7 \%$ working 40 or more hours per week in a range of occupations, including accountant, administrative assistant, nursing, bartender, graphic design, engineering and university faculty. In terms of education, the entire sample had a high school degree or equivalent, $33.5 \%$ had a bachelor's degree and 13.2\% had graduate degrees. Regarding annual household income, $52 \%$ earned $\$ 50,000$ or more per year (13.2\% earned $\$ 100,000$ or more), and $10.3 \%$ of the sample had an income less than $\$ 20,000$ per year. See Table 9 . 


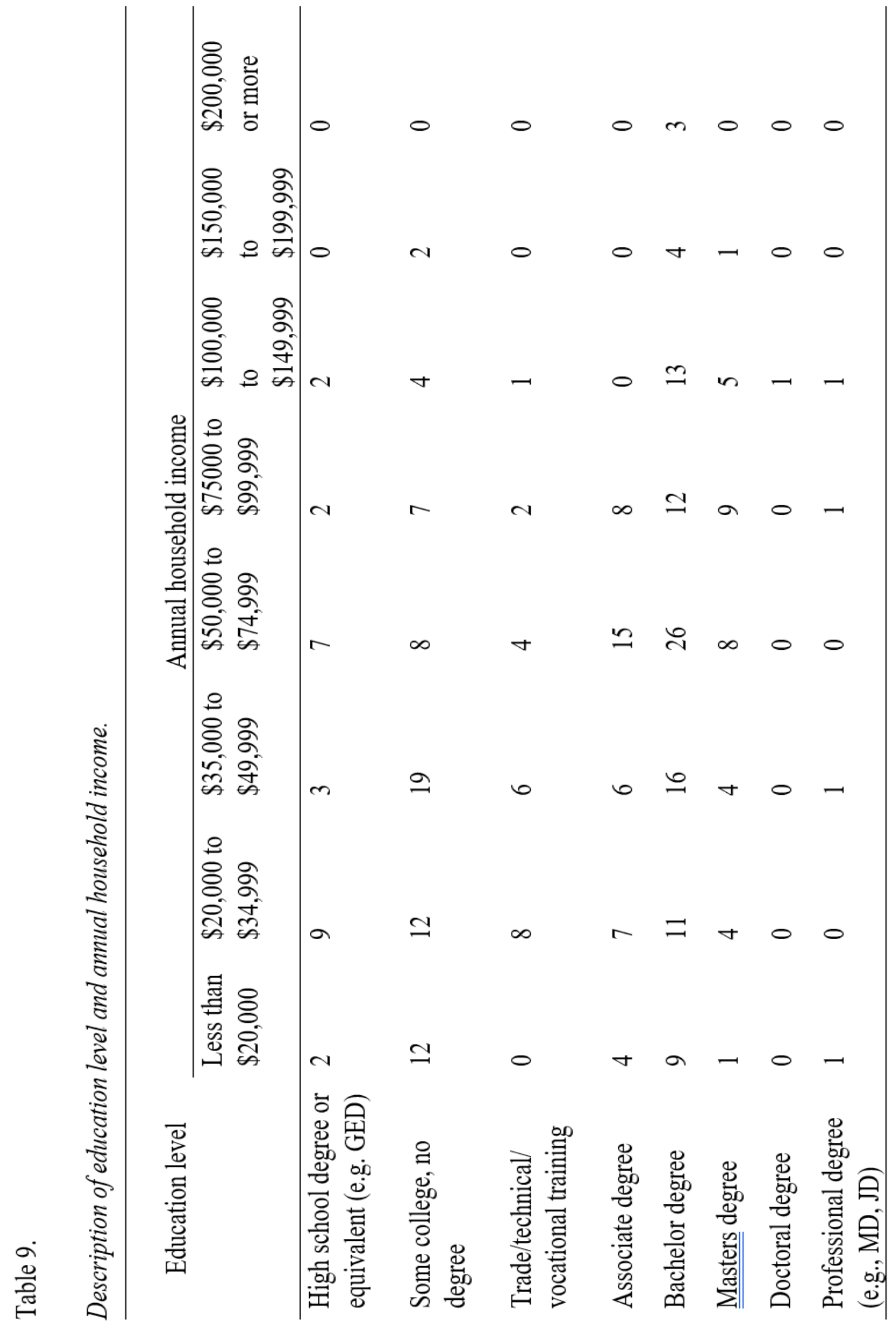


Relatively small percentages of the sample had surgery to have both ovaries removed $(2.1 \%)$, a hysterectomy or other procedure that induced menopause $(4.3 \%)$, or were being treated with hormone replacement therapy $(5.1 \%)$, and $18.5 \%$ were being treated with hormonal contraception such as birth control pills, IUD or birth control injections. The majority of the sample $(77.9 \%)$ reported experiencing at least one hot flash per week, with $14.2 \%$ of the sample experiencing 10 or more hot flashes weekly. Night sweats occurred in $81.1 \%$ of the sample, with $7.1 \%$ experiencing 10 or more night sweats per week. See Table 10.

Thirty-two percent of participants in the sample reported that they had been diagnosed with a chronic illness or condition, of which the highest reported were generalized anxiety disorder (10.3\%) and major depressive disorder (7.8\%). Only $2.8 \%$ of the sample identified as cancer survivors and $31.1 \%$ reported experiencing chronic pain; $6.8 \%$ had been diagnosed with sleep apnea and $10.8 \%$ with restless legs syndrome. See Table 11. 


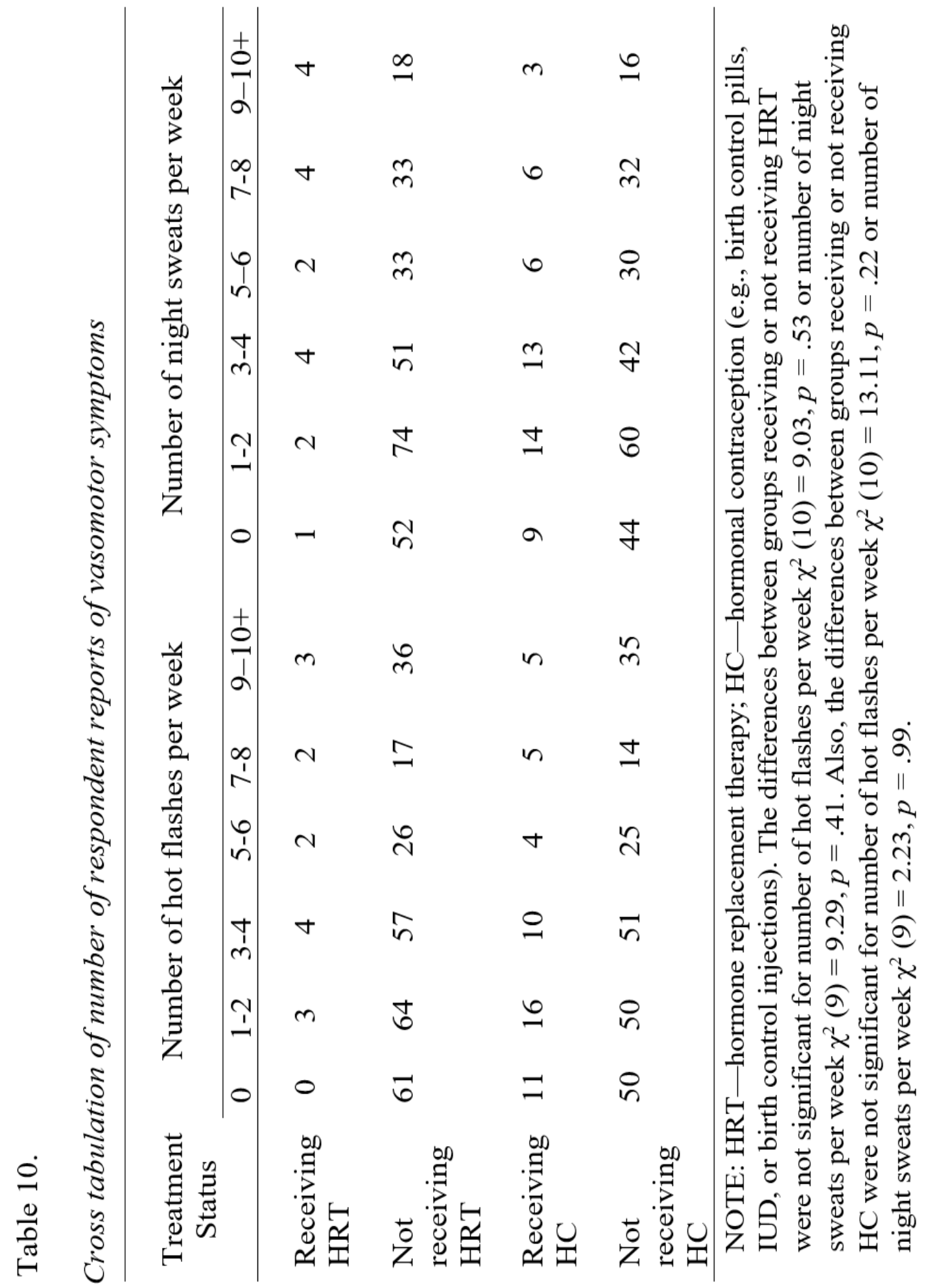


Table 11.

Frequencies of chronic illness and chronic pain among the sample.

\begin{tabular}{ll}
\hline Chronic Condition & \multicolumn{1}{c}{ Frequency } \\
& $\mathrm{n}(\%)$ \\
\hline Generalized Anxiety Disorder & $29(10.3)$ \\
Major Depressive Disorder & $22(7.8)$ \\
Physical Disability* & $11(3.9)$ \\
Diabetes & $14(5)$ \\
Hypertension & $19(6.8)$ \\
Heart Disease & $6(2.1)$ \\
Chronic Obstructive Pulmonary Disease & $1(0.4)$ \\
Asthma & $16(5.7)$ \\
Arthritis & $16(5.7)$ \\
Multiple Sclerosis & $2(0.7)$ \\
Fibromyalgia & $13(4.6)$ \\
Polycystic Ovary Syndrome & $11(3.9)$ \\
Panic Disorder & $16(5.7)$ \\
Cancer Survivor & $8(2.8)$ \\
Chronic Pain & $87(31.1)$ \\
Sleep Apnea & $19(6.8)$ \\
Restless Legs Syndrome & $30(10.7)$ \\
Other** & $36(12.8)$ \\
\hline
\end{tabular}

*Physical disabilities reported include: ankylosing spondylitis, osteoarthritis, cataplexy, degenerative spine disease, endometriosis, hashimoto's thyroiditis, limited mobility in feet and ankles, lumbar radiculopathy, scoliosis, spinal stenosis, and spondylothesis.

**Other chronic conditions reported include: autoimmune condition, B12 deficiency, bipolar disorder, celiac disease, chronic fatigue syndrome, CLL, Crohn's disease, PTSD, endometriosis, eplilepsy, gallstones, GERD, Hashimoto disease, hypothyroidism, IBS, IC, idiopathic small fiber neuropaythy, kidney disease, left bundle branch block, lupus, sjogren's, narcolepsy, NASH, neck pain, rheumatoid arthritis, skin allergies, thyroid disease, UC.

Exploring the weekly use of various substances, $76.8 \%$ of the sample use caffeinated coffee, $56.4 \%$ use caffeinated cola, $37.7 \%$ use wine, $20.1 \%$ use beer, $23.6 \%$ use liquor, and $13.3 \%$ of the sample use marijuana at least one day per week. Twenty-six percent of the sample report smoking currently and $26 \%$ had previously smoked, $48 \%$ percent of the sample had never smoked. 
Regarding exposure to the concept of mindfulness, $37 \%$ reported never hearing of it, $40.2 \%$ had read or heard about mindfulness, $17.8 \%$ considered themselves knowledgeable about mindfulness, $11.7 \%$ practiced mindfulness meditation on their own, and $2.8 \%$ had participated in some form of organized mindfulness practice such as mindfulness-based stress reduction.

\section{Data exploration}

The data were examined to ensure the variables' distributions would not violate statistical assumptions of the analyses to be performed. Skewness and kurtosis levels were determined and visual examination of the shape of the distributions was completed to look for deviations from normality that would significantly affect the analyses (Tabachnick \& Fidell, 2013). Only the CESD, the HFRDIS, and the Negative PANAS scores violated the assumption of normality. Given the relatively large sample size and expected skewness of these data, analyses were conducted with the data in its original form (Field, 2013). Please refer to the supplementary analyses to see primary analyses conducted using the log transformed CESD, HFRDIS, and Negative PANAS data.

\section{Confirmatory Factor Analysis}

To evaluate the structure of the BCS a Confirmatory Factor Analysis (CFA) was used to examine the three factor solution identified in the initial development of the BCS (See Table 1). Maximum likelihood estimation was used to test the three factor CFA solution with Structural Equation Modeling (SEM) using AMOS software version 24 (Bollen, 1989; Byrne, 2013). The previously identified three factor solution was evaluated in terms of global fit, comparative fit indices and individual parameters. Overall, results showed good fit to the data as detailed in the following paragraph. 
Global fit was assessed using the root mean square error of approximation (RMSEA) and observed chi square (Anderson \& Gerbing, 1988; Browne \& Cudeck, 1993). For the three factor CFA model, the RMSEA $=.072(90 \% \mathrm{CI}=0.065-0.080)$. As Browne and Cudeck note, 'a value of about 0.08 or less for the RMSEA would indicate a reasonable error of approximation' (1993, p.144). Another criterion for a good fit is observed chi square divided by degrees of freedom equal to 2.0 or less. In this sample, the value was $2.45($ Chi-square $=557.2, \mathrm{df}=227)$ which approached meeting the 2.0 criterion. The fit can be improved by allowing the errors for 3 pairs of items to be correlated - meaning that people tend to answer several pairs of questions in similar ways. The pairs are: Items 6 and 7, items 8 and 10, and items 20 and 21. When those changes are made, Chi-Square $=453.5, \mathrm{df}=224, \mathrm{RMSEA}=.06$. The value of the observed chi square divided by degrees of freedom improves to 2.02 .

Comparative fit indices were also completed by testing the hypothesized model against more parsimonious models $($ Kenny, 2015). A one factor model $($ Chi-square $=$ 1781.32, $\mathrm{df}=230$, Ratio: 7.74, RMSEA $=.16)$ and a two factor model $($ Chi-square $=$ $1172.9, \mathrm{df}=229$, Ratio: 5.12 , RMSEA $=.12$ ) were examined. The three factor solution is a significantly better fit than either the one or the two factor.

Individual parameters were also examined via factor loadings (Table 12) and factor correlations (Tabachnick \& Fidell, 2013). All were significantly positively correlated with each other, with $r$ 's of .54 (Defusion with Common Humanity), .66 (Common Humanity with Acceptance, and .77 (Defusion with Acceptance). 


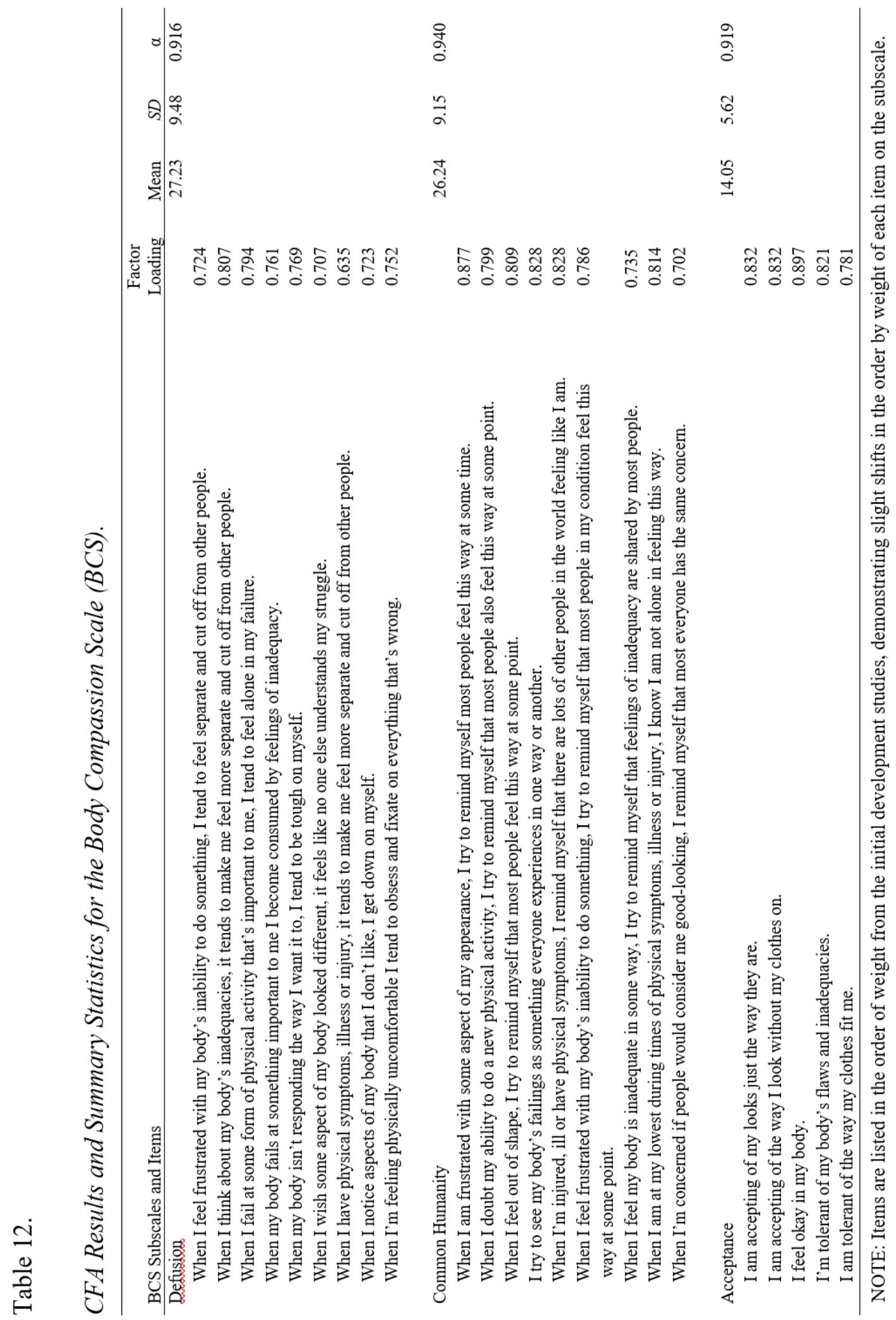


Internal consistency reliability. Cronbach's alpha was used to examine itemtotal correlations to determine the internal consistency of the BCS scores (Cortina, 1993). The following alpha coefficients were obtained for the three subscales/factors of the body compassion scale, demonstrating excellent internal consistency: Defusion $=.92$, Common Humanity $=.94$, Acceptance $=.92$. The Cronbach's alpha of 0.95 for all 23 items is excellent, supporting use of a total score.

Validity. Associations between BCS scores and each of the other measures were examined to determine if there is support for the BCS's concurrent validity (Cronbach \& Meehl, 1955; Messick, 1995). Body compassion was related to associated measures of perimenopause, body image and mindfulness-acceptance in the expected directions. Correlations between body compassion total and subscale scores and other relevant constructs are presented in Table 13. All correlations were in the expected directions and were moderate to large. These findings indicate that body compassion and its factors/subscales show predicted relationships with other variables. 
Table 13.

Correlations between body compassion, subscales and other measures.

\begin{tabular}{|c|c|c|c|c|}
\hline Measures & $\begin{array}{c}\text { Body } \\
\text { Compassion } \\
\text { Total }\end{array}$ & Defusion & $\begin{array}{l}\text { Common } \\
\text { Humanity }\end{array}$ & Acceptance \\
\hline \multicolumn{5}{|l|}{$\begin{array}{l}\text { Predicted positive } \\
\text { correlations }\end{array}$} \\
\hline SCS & $.833 * * *$ & $.793 * * *$ & $.645 * * *$ & $.684 * * *$ \\
\hline FFMQ & $.582 * * *$ & $.575 * * *$ & $.443 * * *$ & $.472 * * *$ \\
\hline BI-AAQ & $.683 * * *$ & $.736 * * *$ & $.367 * * *$ & $.688 * * *$ \\
\hline BAS-2 & $.774 * * *$ & $.675 * * *$ & $.583 * * *$ & $.779 * * *$ \\
\hline $\mathrm{PA}$ & $.554 * * *$ & $.493 * * *$ & $.454 * * *$ & $.486 * * *$ \\
\hline APPEVAL & $.730 * * *$ & $.632 * * *$ & $.509 * * *$ & $.798 * * *$ \\
\hline BASS & $.689 * * *$ & $.635 * * *$ & $.458 * * *$ & $.729 * * *$ \\
\hline \multicolumn{5}{|l|}{$\begin{array}{l}\text { Predicted negative } \\
\text { correlations }\end{array}$} \\
\hline BMI & $-.208 * *$ & $-.174 * *$ & $-.082 *$ & $-.266 * *$ \\
\hline MRS & $-.371 * * *$ & $-.477 * * *$ & $-.148^{*}$ & $-.318 * * *$ \\
\hline CESD & $-.471 * * *$ & $-.576 * * *$ & $-.239 * * *$ & $-.373 * * *$ \\
\hline HFRDIS & $-.229 * * *$ & $-.322 * * *$ & -.058 & $-.205 * *$ \\
\hline NA & $-.399 * * *$ & $-.472 * * *$ & $-.200 * *$ & $-.358 * * *$ \\
\hline APPOR & -.082 & -.084 & .027 & $-.207 *$ \\
\hline OWPREOC & $-.508 * * *$ & $-.480 * * *$ & $-.296 * * *$ & $-.584 * * *$ \\
\hline SCW & $-.374 * * *$ & $.337 * * *$ & $-.244 * * *$ & $-.415 * * *$ \\
\hline
\end{tabular}

NOTE: SCS--Self-Compassion Scale; FFMQ--Five Facet Mindfulness Questionnaire; BI-AAQ-Body Image-Acceptance and Action Questionnaire; BAS2-Body Appreciation Scale; PA-PANAS Positive Affect; APPEVAL_-Appearance Evaluation; BASS — Body Areas Satisfaction Scale; BMI--Body Mass Index; MRS - Menopause Rating Scale; CESD — Center for Epidemiological Study of Depression; HFRDIS - Hot Flash Rating of Daily Interference Scale; NA--PANAS Negative Affect; APPOR-Appearance Orientation; OWPREOC-Overweight Preoccupation; SCW-Self Classified Weight

$* p<.05 . * * p<.01 . * * * p<.001$

\section{Supplementary analyses}

As the development of the BCS continues, particularly through cross-validation studies in varying samples, it is important to continually consider the utility and evolution of the scale with each particular population sampled, and in general. In addition to 
examining a second-order CFA and conducting checks on the decision to use non-normal data without transformation, these supplementary analyses also begin to explore these considerations of utility and evolution through a brief comparison of the BCS in this sample of women in perimenopause with results from the first CFA, which was conducted in a sample of undergraduate students.

\section{Sample comparison.}

The first CFA of the BCS was conducted in a sample of 258 undergraduate females $(n=186)$ and males $(n=72)$. The mean age of the undergraduate sample was $20.24(S D=4.16)$ and the mean BMI was $24.26(S D=4.43)$. This represents a substantially different cross-section than this sample of women in perimenopause with a mean age of $42.92(S D=9.71 ; t(537)=34.71, \mathrm{p}<.0001)$ and mean BMI of $28.30(S D=$ $7.36 ; t(537)=7.64, \mathrm{p}<.0001)$. Regarding the racial diversity of each sample, the undergraduate sample was $82.7 \%$ White, $8.7 \%$ Black, $4.3 \%$ Asian, $2.8 \%$ Hispanic, $0.4 \%$ American Indian/Alaska Native, and 1.2\% selected 'Other'; and the current sample of women in perimenopause was $83.6 \%$ White, $10 \%$ Black, $5.3 \%$ Hispanic, $3.2 \%$ American Indian/Alaska Native, $1.8 \%$ Asian, and 1.8\% selected 'Other.'

There was a significant difference $(t(535)=-3.60, \mathrm{p}<.001)$ in the undergraduate body compassion scores $(M=73.33, S D=16.29)$ and the body compassion scores of women in perimenopause $(M=67.49, S D=20.75)$. See table 14 for comparisons of subscale scores between the two samples. 
Table 14.

Comparisons of body compassion subscale scores between an undergraduate sample and this sample of women in perimenopause.

\begin{tabular}{lccc}
\hline \multicolumn{1}{c}{ Sample } & $\begin{array}{c}\text { Defusion } \\
\mathrm{M}(\mathrm{SD})\end{array}$ & $\begin{array}{c}\text { Common Humanity } \\
\mathrm{M}(\mathrm{SD})\end{array}$ & $\begin{array}{c}\text { Acceptance } \\
\mathrm{M}(\mathrm{SD})\end{array}$ \\
\hline $\begin{array}{l}\text { Undergraduates } \\
\begin{array}{l}\text { Women in } \\
\text { perimenopause }\end{array}\end{array}$ & $28.10(8.86)$ & $28.21(7.53)$ & $16.64(4.70)$ \\
$t$-test & $27.23(9.48)$ & $26.24(9.15)$ & $14.02(5.62)$ \\
& $\begin{array}{c}t(535)=-1.10, \\
\mathrm{p}=0.27\end{array}$ & $t(535)=-2.71, \mathrm{p}<.01$ & $\begin{array}{c}t(535)=-5.83, \\
\mathrm{p}<.001\end{array}$ \\
\hline
\end{tabular}

Additionally, in the undergraduate sample, males scored significantly higher on the BCS $(M=78.20, S E=1.82)$ than did females $(M=71.35, S E=1.25)$. This difference was significant, $t(237)=2.998, p<.01$.

Second order CFA. A second order CFA was used to investigate body compassion as a second order factor to the three factor solution identified in the initial development of the BCS and validated in this study. As would be expected of a second order model with only three factors, the fit was identical $(\mathrm{RMSEA}=.072,90 \% \mathrm{CI}=$ 0.065-0.080; Chi-square $=557.2, \mathrm{df}=227)$ to the first order model with correlated factors identified in the primary analyses. The second order model was used to examine the factor loadings of the first order factors (defusion, common humanity, acceptance) on the second order factor of body compassion. The following factor loadings do support an adequate second order model, and are compelling enough to favor interpretation of the second order model: defusion $=.79$, common humanity $=.68$, acceptance $=.97$ (Alasuutari, Bickman, \& Brannen, 2008).

Correlations utilizing log transformed data. Associations between BCS scores and the log transformed CESD, HFRDIS, and Negative PANAS were examined in 
comparison with the associations identified with the non-transformed data from these measures. As seen in Table 15, performing the log transformation on these three variables did not impact whether or not an association was significant. The log transformation did impact the level of significance for three associations: HFRDIS — BCS Total, HFRDIS Acceptance, NA — Common Humanity.

Table 15.

Correlations between body compassion, subscales and log transformed measures.

\begin{tabular}{lcccc}
\hline Measures & $\begin{array}{c}\text { Body } \\
\text { Compassion } \\
\text { Total }\end{array}$ & Defusion & $\begin{array}{c}\text { Common } \\
\text { Humanity }\end{array}$ & Acceptance \\
\hline $\begin{array}{l}\text { Non-transformed scores } \\
\text { CESD }\end{array}$ & $-.471 * * *$ & $-.576 * * *$ & $-.239 * * *$ & $-.373 * * *$ \\
HFRDIS & $-.229 * * *$ & $-.322^{* * *}$ & -.058 & $-.205 * *$ \\
NA & $-.399 * * *$ & $-.472 * * *$ & $-.200 * *$ & $-.358 * * *$ \\
\hline Log transformed scores & & & & \\
CESD & $-.481 * * *$ & $-.593 * * *$ & $-.243 * * *$ & $-.379 * * *$ \\
HFRDIS & $-.203 * *$ & $-.273 * * *$ & -.069 & $-.159 *$ \\
NA & $-.425 * * *$ & $-.502 * * *$ & $\mathbf{- . 2 1 6 * * *}$ & $-.376 * * *$ \\
\hline
\end{tabular}

NOTE: CESD — Center for Epidemiological Study of Depression; HFRDIS — Hot Flash Rating of Daily Interference Scale; NA--PANAS Negative Affect; correlations impacted by log transformation are noted in bold. $* p<.05 . * * p<.01 . * * * p<.001$

\section{Exploratory analyses}

Given the age range of the sample was broader than expected $(19-67$ years $)$, it is possible that a portion of the participants ages 40 or younger were experiencing irregularities in their menstrual cycle due to hormonal contraception rather than perimenopause. Just over one third of the sample (37.4\%) were ages 40 and under ( $\mathrm{n}=$ $105)$ with the remaining $62.6 \%$ being over the age of $40(n=176)$. Exploratory analyses were conducted to examine potential differences by age cohort. Additionally, a series of 
regressions was conducted to explore the potential predictive validity of the BCS in symptoms/characteristics of perimenopause.

Although these analyses do not impact the validation of the BCS, these results may be important to note for discussions related to the experience of perimenopause.

Age group comparisons. On average, participants over the age of 40 experienced more vasomotor symptoms $(M=10.2, S E=0.45)$ than did those participants ages 40 and under $(M=7.33, S E=0.49)$. This difference was significant $t(278)=-$ $4.128, p<.001$. However, in overall menopausal related symptoms as measured by the MRS, there was not a significant difference $t(273)=0.91, p=.365$ between those over the age of $40(M=24.6, S E=0.52)$ and those ages 40 and under $(M=25.31, S E=0.66)$. Additionally, there was not a significant difference between the two age cohorts and whether or not they were being treated by HRT $\chi^{2}(1)=0.50, p=.48$. There was, however, a significant difference between the two age cohorts and whether or not they were being treated with hormonal contraception (e.g., birth control pills, IUD, or birth control injections) $\chi^{2}(1)=22.38, p<.001$. Given that menstrual cycle irregularity and/or more than three months elapsed between periods may be consequences of some hormonal contraceptions, potential differences were explored. There were no significant differences between being treated with hormonal contraceptions and menstrual cycle irregularity $\chi^{2}$ $(2)=0.62, p=.74$; nor between hormonal contraceptions and more than three months elapsed since the last period $\chi^{2}(2)=4.76, p=.09$.

Moving beyond vasomotor symptoms, also explored were potential differences in age cohort and depression and sleep quality, other key characteristics of perimenopause. On average, participants over the age of 40 experienced fewer depressive symptoms as 
measured by the CESD $(M=30.50, S E=0.81)$ than did those participants ages 40 and under $(M=35.26, S E=1.17)$. This difference was significant $t(267)=3.45, p<.01$. However, in sleep quality as measured by the PSQI, there was not a significant difference $t(249)=0.29, p=.77$ between those over the age of $40(M=10.36, S E=0.33)$ and those ages 40 and under $(M=10.52, S E=0.41)$.

Additionally, there was no significant difference between the two age cohorts and level of body compassion $(t(279)=-1.72, p=.074)$; however, there was a significant difference in the defusion subscale of the BCS $(t(279)=-2.51, p<.05)$ between those women over the age of $40(M=28.31, S E=0.76)$ and those ages 40 and under $(M=$ 25.41, $S E=0.80)$

Potential predictive validity of body compassion. Given that the foundation of body compassion is a bridge between two different theoretical foundations - cognitivebehavioral and buddhist psychology_additional analyses were conducted to further ascertain the unique contribution of body compassion to the prediction and understanding of various outcomes above and beyond more established measures of body image and self-compassion. To this end, given the use of subscales of the MBSRQ and SCS in the literature, as well as clarifying the contribution of each factor to the predictive utility of the BCS, subscales of these three measures were included in these exploratory analyses.

A series of multiple regressions were employed to explore the potential predictive validity of the BCS, above and beyond existing measures of body image and selfcompassion, of symptoms/characteristics of perimenopause. Notably, Field (2013) suggests that in such exploratory regressions, utilizing the backward stepwise method is appropriate. Bivariate correlations indicate no issues of multicollinearity between the 
subscales, with only the AE and BASS subscales of the MBSRQ-AS correlating above .80 (Field, 2013; See Table 16). 


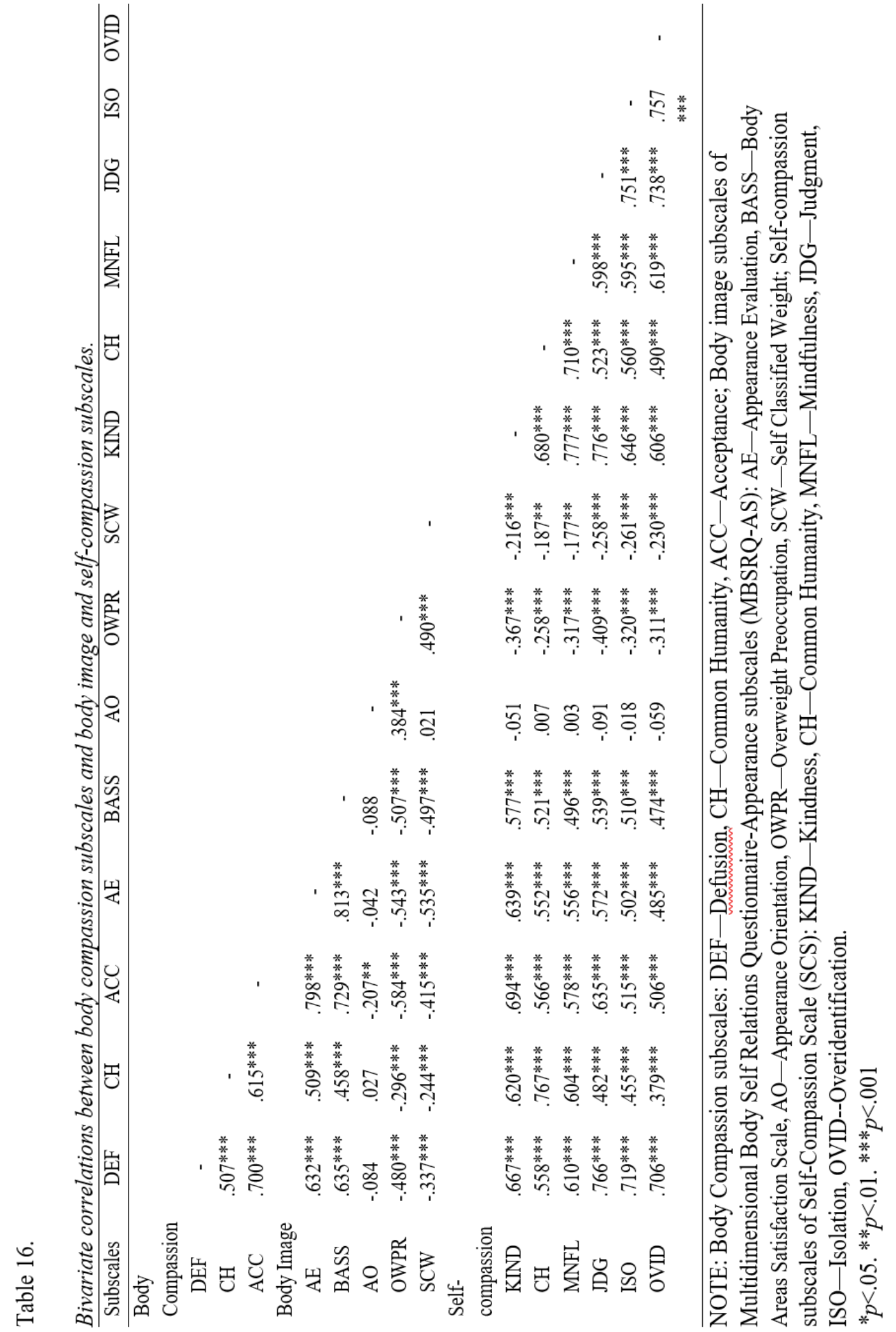


Given the identified primary symptoms/characteristics of perimenopause which influence various health outcomes, these were each examined individually, in addition to overall distress related to perimenopause as measured by the MRS. A summary of the predictor variables retained in each model is provided in Table 17.

Table 17.

Summary of predictor variables retained in models predicting perimenopause outcomes.

\begin{tabular}{|c|c|c|c|c|}
\hline & $\begin{array}{l}\text { Vasomotor } \\
\text { Symptoms }\end{array}$ & $\begin{array}{c}\text { Sleep } \\
\text { Quality }\end{array}$ & Depression & $\begin{array}{c}\text { Menopause-related } \\
\text { quality of life }\end{array}$ \\
\hline $\begin{array}{l}\text { MBSRQ- } \\
\text { AS } \\
\text { and } \\
\text { BCS }\end{array}$ & $\begin{array}{l}\text {-BCS-Defusion } \\
\text {-BCS-Common } \\
\text { Humanity* } \\
\text {-BCS- } \\
\text { Acceptance* }\end{array}$ & $\begin{array}{l}\text {-Appearance } \\
\text { Orientation } \\
\text {-BCS- } \\
\text { Defusion*** }\end{array}$ & $\begin{array}{l}\text {-Appearance } \\
\text { Orientation } \\
\text {-BCS-Defusion*** }\end{array}$ & $\begin{array}{l}\text {-Appearance } \\
\text { Orientation*** } \\
\text {-BCS-Defusion*** } \\
\text {-BCS-Common } \\
\text { Humanity** } \\
\text {-BCS-Acceptance }\end{array}$ \\
\hline $\begin{array}{l}\text { SCS } \\
\text { and } \\
\text { BCS }\end{array}$ & $\begin{array}{l}\text {-BCS-Defusion } \\
\text {-BCS-Common } \\
\text { Humanity* } \\
\text {-BCS-Acceptance }\end{array}$ & $\begin{array}{l}\text {-Common } \\
\text { Humanity } \\
\text {-BCS- } \\
\text { Defusion*** }\end{array}$ & $\begin{array}{l}\text {-Mindfulness } \\
\text {-Isolation* } \\
\text {-Overidentification* } \\
\text {-BCS-Defusion*** } \\
\text {-BCS-Common } \\
\text { Humanity* }\end{array}$ & $\begin{array}{l}\text {-Over- } \\
\text { identification** } \\
\text {-BCS-Defusion*** } \\
\text {-BCS-Common } \\
\text { Humanity }\end{array}$ \\
\hline
\end{tabular}

Note: MBSRQ-AS subscales - appearance orientation, appearance evaluation, weight classification, overweight preoccupation, body areas satisfaction scale; SCS subscales - kindness, common humanity, mindfulness, judgment, isolation, overidentification; BCS subscales defusion, common humanity, acceptance.

$* p<.05, * * p<.01, * * * p<.001$ 
Vasomotor symptoms. A backward regression was conducted to examine the influence of each of the MBSRQ-AS subscales (appearance orientation, appearance evaluation, weight classification, overweight preoccupation, and body areas satisfaction scale) and each of the BCS subscales (defusion, common humanity, acceptance) on the dependent variable - vasomotor symptoms (total weekly frequency of hot flashes and night sweats). Three predictor variables were retained in the final model-defusion, common humanity and acceptance subscales of the $\operatorname{BCS}\left(R^{2}=.07, \mathrm{~F}(3,255)=6.40, p<\right.$ .001). The BCS common humanity subscale was a significant predictor of vasomotor symptoms $(\beta=.11, \mathrm{p}<.05)$; the defusion $(\beta=-.10, \mathrm{p}=.05)$ and acceptance $(\beta=-.20, \mathrm{p}=$ .10) subscales were not significant predictors. See Table 18.

Table 18.

Backward regression model predicting vasomotor symptoms with MBSRQ-AS and BCS subscales.

\begin{tabular}{lcc}
\hline & Standardized $\beta$ & Adjusted $^{2}$ \\
\hline First model with all variables & & .052 \\
Appearance Evaluation & .152 & \\
Appearance Orientation & -.083 & \\
Body Areas Satisfaction Scale & -.105 & \\
Overweight Preoccupation & .102 & \\
Weight Classification & -.043 & \\
BCS - Defusion & -.141 & \\
BCS - Common Humanity & $.164^{*}$ & .059 \\
BCS - Acceptance & -.229 & \\
Final model & & \\
BCS - Defusion & -.167 & \\
BCS - Common Humanity & $.168^{*}$ & \\
BCS - Acceptance & $-.191^{*}$ & \\
\end{tabular}

Note: DV: Vasomotor Symptoms, IVs: MBSRQ-AS subscales - appearance orientation, appearance evaluation, weight classification, overweight preoccupation, body areas satisfaction scale; BCS subscales - defusion, common humanity, acceptance.

$* p<.05, * * p<.01, * * * p<.001$ 
A backward regression was conducted to examine the influence of each of the SCS subscales (self-kindness, self-judgment, common humanity, isolation, mindfulness, over-identification) and each of the BCS subscales on vasomotor symptoms. The final model retained three predictor variables, the defusion, common humanity and acceptance subscales of the BCS $\left(R^{2}=.065, \mathrm{~F}(3,262)=6.09, p<.01\right)$. The BCS common humanity subscale was a significant predictor of vasomotor symptoms $(\beta=.16, p<.05)$; the defusion $(\beta=-.17, \mathrm{p}=.05)$ and acceptance $(\beta=-.18, \mathrm{p}=.05)$ subscales were not significant predictors. See Table 19.

Table 19.

Backward regression model predicting vasomotor symptoms with SCS and BCS subscales.

\begin{tabular}{lcc}
\hline & Standardized $\beta$ & Adjusted $\mathrm{R}^{2}$ \\
\hline First model with all variables & & .044 \\
Kindness & -.036 & \\
Common Humanity & .112 & \\
Mindfulness & -.042 & \\
Judgment & .159 & \\
Isolation & -.026 & \\
Overidentification & .006 & \\
BCS - Defusion & $-.249 *$ & \\
BCS - Common Humanity & .105 & .054 \\
BCS - Acceptance & -.189 & \\
Final model & & \\
BCS - Defusion & -.165 & \\
BCS - Common Humanity & $.159 *$ & \\
BCS - Acceptance & -.178 &
\end{tabular}

Note: DV: Vasomotor Symptoms, IVs: SCS subscales - kindness, common humanity, mindfulness, judgment, isolation, overidentification; BCS subscales - defusion, common humanity, acceptance.

$* p<.05, * * p<.01, * * * p<.001$ 
Sleep quality. A backward regression was conducted to examine the influence of the MBSRQ-AS subscales and each of the BCS subscales on sleep quality as measured by the PSQI. The final model retained two predictor variables, the appearance orientation subscale of the MBSRQ-AS and the defusion subscale of the BCS $\left(R^{2}=.166, \mathrm{~F}(2,227)\right.$ $=22.59, p<.001)$. The BCS defusion subscale was a significant predictor of sleep quality $(\beta=-.40, \mathrm{p}<.001)$, and the MBSRQ-AS appearance orientation subscale $(\beta=-.09, \mathrm{p}=$ .12) was not a significant predictor. See Table 20.

Table 20.

Backward regression model predicting sleep quality with MBSRQ-AS and BCS subscales.

\begin{tabular}{lcc}
\hline & Standardized $\beta$ & Adjusted R \\
\hline First model with all variables & & .149 \\
Appearance Evaluation & .099 & \\
Appearance Orientation & -.079 & \\
Body Areas Satisfaction Scale & -.114 & \\
Overweight Preoccupation & -.097 & \\
Weight Classification & .037 & \\
BCS - Defusion & $-.342^{* * *}$ & \\
BCS - Common Humanity & $.002^{*}$ & .159 \\
BCS - Acceptance & -.124 & \\
Final model & & \\
Appearance Orientation & -.094 & \\
BCS - Defusion & $-.404^{* * *}$ & \\
\end{tabular}

Note: DV: Sleep quality, IVs: MBSRQ-AS subscales - appearance orientation, appearance evaluation, weight classification, overweight preoccupation, body areas satisfaction scale; BCS subscales - defusion, common humanity, acceptance.

$* p<.05, * * p<.01, * * * p<.001$ 
A backward regression was conducted to examine the influence of the SCS and BCS subscales on sleep quality. The final model retained two predictor variables, the common humanity subscale of the SCS and the defusion subscale of the BCS $\left(R^{2}=.148\right.$, $\mathrm{F}(2,235)=20.41, p<.001)$. The BCS defusion subscale was a significant predictor of sleep quality $(\beta=-.30, \mathrm{p}<.001)$, and the SCS common humanity subscale $(\beta=-.12, \mathrm{p}=$ .10) was not a significant predictor. See Table 21.

Table 21.

Backward regression model predicting sleep quality with SCS and BCS subscales.

\begin{tabular}{llc}
\hline & Standardized $\beta$ & Adjusted $\mathrm{R}^{2}$ \\
\hline First model with all variables & & .129 \\
Kindness & .019 & \\
Common Humanity & -.213 & \\
Mindfulness & .096 & \\
Judgment & -.178 & \\
Isolation & .059 & \\
Overidentification & -.010 & \\
BCS - Defusion & $-.234^{*}$ & \\
BCS - Common Humanity & .078 & .141 \\
BCS - Acceptance & -.038 & \\
Final model & & \\
Common Humanity & -.122 & \\
BCS - Defusion & $-.302 * * *$ & \\
\end{tabular}

Note: DV: Sleep quality, IVs: SCS subscales - kindness, common humanity, mindfulness, judgment, isolation, overidentification; BCS subscales - defusion, common humanity, acceptance.

$* p<.05, * * p<.01, * * * p<.001$ 
Depression. A backward regression was conducted to examine the influence of the MBSRQ-AS subscales and each of the BCS subscales on depression as measured by the CESD. The final model retained two predictor variables, the appearance orientation subscale of the MBSRQ-AS and the defusion subscale of the BCS $\left(R^{2}=.351, \mathrm{~F}(2,245)\right.$ $=66.37, p<.001)$. Both the BCS defusion subscale $(\beta=-.59, \mathrm{p}<.001)$ and the MBSRQAS appearance orientation subscale $(\beta=-.17, \mathrm{p}<.01)$ were significant predictors. See Table 22.

Table 22.

Backward regression model predicting depression with MBSRQ-AS and BCS subscales.

\begin{tabular}{llc}
\hline & Standardized $\beta$ & Adjusted $\mathrm{R}^{2}$ \\
\hline First model with all variables & & .344 \\
Appearance Evaluation & -.045 & \\
Appearance Orientation & $-.160^{* *}$ & \\
Body Areas Satisfaction Scale & -.052 & \\
Overweight Preoccupation & -.049 & \\
Weight Classification & -.082 & \\
BCS - Defusion & $-.599 * * *$ & .346 \\
BCS - Common Humanity & .108 & \\
BCS - Acceptance & -.044 & \\
Final model & & \\
Appearance Orientation & -.166 & \\
BCS - Defusion & $-.585^{* * *}$ & \\
& & \\
\hline
\end{tabular}

Note: DV: Depression, IVs: MBSRQ-AS subscales - appearance orientation, appearance evaluation, weight classification, overweight preoccupation, body areas satisfaction scale; BCS subscales - defusion, common humanity, acceptance.

$* p<.05, * * p<.01, * * * p<.001$ 
A backward regression was conducted to examine the influence of the SCS and BCS subscales on depression as measured by the CESD. The final model retained five predictor variables, the isolation, mindfulness and over-identification subscales of the SCS and the common humanity and defusion subscales of the BCS $\left(R^{2}=.401, \mathrm{~F}(5,250)\right.$ $=33.45, p<.001)$. Significant predictors include the isolation $(\beta=-.20, \mathrm{p}<.05)$ and over-identification $(\beta=-.18, \mathrm{p}<.05)$ subscales of the SCS, as well as the defusion $(\beta=-$ $.31, \mathrm{p}<.001)$ and common humanity $(\beta=.15, \mathrm{p}<.05)$ subscales of the BCS. The mindfulness subscale of the SCS was not a significant predictor $(\beta=-.12, p=.109)$. See

Table 23.

Table 23.

Backward regression model predicting depression with SCS and BCS subscales.

\begin{tabular}{lcc}
\hline & Standardized $\beta$ & Adjusted $\mathrm{R}^{2}$ \\
\hline First model with all variables & .119 & .387 \\
Kindness & -.101 & \\
Common Humanity & -.150 & \\
Mindfulness & -.148 & \\
Judgment & -.157 & .389 \\
Isolation & -.146 \\
Overidentification & $-.289^{* *}$ \\
BCS - Defusion & $.188^{*}$ \\
BCS - Common Humanity & .031 \\
BCS - Acceptance & \\
Final model & -.120 \\
Mindfulness & $-.196^{*}$ \\
Isolation & $-.180^{*}$ \\
Overidentification & $-.306^{* * *}$ \\
BCS - Defusion & $.153^{*}$ \\
BCS - Common Humanity & \\
\hline Note: DV: Depression, IVs: SCS subscales - kindness, common humanity, mindfulness, \\
judgment, isolation, overidentification; BCS subscales - defusion, common humanity, \\
acceptance.
\end{tabular}


Menopause related quality of life. A backward regression was conducted to examine the influence of the MBSRQ-AS and the BCS subscales on health related quality of life as measured by the MRS. The final model retained the MBSRQ-AS appearance orientation subscale and the three BCS subscales as predictor variables $\left(R^{2}=\right.$ $.291, \mathrm{~F}(4,250)=25.62, p<.001)$ and significant predictors in the model include the MBSRQ-AS appearance orientation subscale $(\beta=-.26, \mathrm{p}<.001)$, and the BCS defusion $(\beta=-.48, p<.001)$ and common humanity $(\beta=.18, p<.01)$ subscales. The BCS acceptance subscale $(\beta=-.14, p=.094)$ was not a significant predictor.

Table 24.

Backward regression model predicting menopause related quality of life with MBSRQ-AS and BCS subscales.

\begin{tabular}{llc}
\hline & Standardized $\beta$ & Adjusted $\mathrm{R}^{2}$ \\
\hline First model with all variables & & .271 \\
Appearance Evaluation & .004 & \\
Appearance Orientation & $-.256^{* * *}$ & \\
Body Areas Satisfaction Scale & -.084 & \\
Overweight Preoccupation & .005 & \\
Weight Classification & .000 & .279 \\
BCS - Defusion & $-.457^{* * *}$ & \\
BCS - Common Humanity & $.178^{*}$ & \\
BCS - Acceptance & -.094 & \\
Final model & & \\
Appearance Orientation & $-.259 * * *$ & \\
BCS - Defusion & $-.478^{* * *}$ & \\
BCS - Common Humanity & $.184^{* *}$ & \\
BCS - Acceptance & -.144 & \\
\hline
\end{tabular}

Note: DV: Menopause-related quality of life, IVs: MBSRQ-AS subscales - appearance orientation, appearance evaluation, weight classification, overweight preoccupation, body areas satisfaction scale; BCS subscales - defusion, common humanity, acceptance.

$* p<.05, * * p<.01, * * * p<.001$ 
A backward regression was conducted to examine the influence of the SCS and the BCS subscales on health related quality of life as measured by the MRS. The final model retained the SCS over-identification subscale and the BCS defusion and common humanity subscales as predictor variables $\left(R^{2}=.251, \mathrm{~F}(3,259)=28.90, p<.001\right)$.

Significant predictors in the model include the SCS over-identification subscale $(\beta=-.21$, $\mathrm{p}<.01)$, and the BCS defusion subscale $(\beta=-.38, \mathrm{p}<.001)$. The BCS common humanity subscale $(\beta=.12, p=.05)$ was not a significant predictor.

Table 25 .

Backward regression model predicting menopause related quality of life with SCS and BCS subscales.

\begin{tabular}{lcc}
\hline & Standardized $\beta$ & Adjusted R $^{2}$ \\
\hline First model with all variables & .102 & .230 \\
Kindness & -.070 & \\
Common Humanity & -.052 & \\
Mindfulness & -.035 & \\
Judgment & -.049 & \\
Isolation & -.171 & .242 \\
Overidentification & $-.332^{* *}$ \\
BCS - Defusion & .174 & \\
BCS - Common Humanity & -.056 & \\
BCS - Acceptance & & \\
Final model & $-.212^{* *}$ & \\
Overidentification & $-.378^{* * *}$ \\
BCS - Defusion & .121 & \\
BCS - Common Humanity & & \\
&
\end{tabular}

Note: DV: Menopause-related quality of life, IVs: SCS subscales - kindness, common humanity, mindfulness, judgment, isolation, overidentification; BCS subscales - defusion, common humanity, acceptance.

$* p<.05, * * p<.01, * * * p<.001$ 


\section{CHAPTER IV}

\section{DISCUSSION}

The BCS was designed for use in research, clinical assessment and intervention regarding the role of body compassion in understanding, preventing, and enhancing health promoting behaviors, psychological wellbeing and/or quality of life. A three factor solution of the BCS had previously been identified and confirmed in two distinct samples of undergraduates (Altman et. al., 2017). The present study is a cross-validation of the BCS in a sample of women in perimenopause - a key developmental period in a woman's life which presents an ever-changing milieu of physical manifestations of shifting hormones and an aging body. Given the significance of the body in the experience of perimenopause, women in perimenopause are an ideal population for crossvalidation of the BCS.

This chapter will discuss the implications of the results of this cross validation study. Limitations and strengths of the study will be reviewed, as well as future directions in the evolution of the BCS, its structure, use and application.

\section{Sample characteristics}

Among the demographic variables in this study, the age of the sample was particularly noticeable. With a mean age of 42.92 and a range of age from 19-67, this sample was slightly younger than was anticipated, with rough estimates that most women enter menopause in their mid to late-40s (den Tonkelaar, te Velde, \& Looman, 1998; Fuh 
et al., 2006), it is possible this sample is not representative of the average perimenopausal experience of women who are at least half-way through this time of transition. However, as the average age of menarche has declined, it is possible the women are also entering perimenopause at younger ages (den Tonkelaar, te Velde, \& Looman, 1998; Fuh et al., 2006; Morris et al., 2007).

It is estimated that in more economically developed countries between $20-45 \%$ of women will have a hysterectomy by the time they are 60-70 years old (Wilson \& Mishra, 2016). This is substantially more than the $4.3 \%$ of the current sample of women in perimenopause who report having a hysterectomy or other procedure that induced menopause. Granted, the current sample had a mean age of 42.92 years, however, it was anticipated there would be higher numbers of hysterectomies and similar procedures in the sample. A substantially higher percentage (18.5\%) of the current sample were being treated with hormonal contraception - a number that may be reflective of the growing evidence in support of the use of hormone therapy for the alleviation of symptoms associated with the menopausal transition (Schmidt, 2016). The primary indication for hormone therapy is the treatment of moderate to severe vasomotor symptoms (Schmidt, 2016), which appears to be reflected in the current sample, although not significant, fewer vasomotor symptoms were reported by women being treated with HC than by women not receiving $\mathrm{HC}$ treatment (see Table 10).

Also of note is the $32 \%$ of the sample reporting having been diagnosed with a chronic illness or condition, with the highest reported being generalized anxiety disorder (GAD) and major depressive disorder (MDD). This presents an interesting overlap with known symptomatology of perimenopause and prompts the question of a potential 
feedback loop with the physiological symptoms of perimenopause - if the GAD/MDD is preexisting, it likely impacts the experience of women in perimenopause. Similarly, with $31 \%$ of the sample reporting chronic pain, this alone may have implications for how one might experience this time of transition.

\section{Confirmatory Factor Analysis}

The three factor structure of the BCS previously identified and validated in undergraduate samples actually exhibited better fit in this sample of women in perimenopause. Defusion, common humanity and acceptance were confirmed as distinct factors of body compassion. This cross-validation of the BCS is encouraging in the application of body compassion and the BCS with real world samples of adults.

Defusion is a component of body compassion that is comparable to the notion of defusion put forth in Acceptance and Commitment Therapy (Hayes et al., 2012). It refers to the ability to experience one's body from the stance of an observer, rather than as the body itself. An increase in defusion is associated with decreased attachment to body image evaluations as "truth," thereby loosening the grip these evaluations (positive or negative) have on one's global self-concept. An example item from the defusion subscale of the BCS is "When my body fails at something important to me I become consumed by feelings of inadequacy." Interestingly, the items with the highest loading among both the undergraduate sample and the sample of women in perimenopause, both ended with feeling "separate and cut off from other people." However, the key statement on this item for the undergraduates was "When I feel frustrated with my body's inability to do something..." while for women in perimenopause it was "When I think about my body's

inadequacies..." Also, the item with the lowest factor loading for undergraduates was the 
middle item for women in perimenopause, "When I'm feeling physically uncomfortable I tend to obsess and fixate on everything that's wrong." Taken together these suggest that among midlife women there may be a shift toward a certain vigilance of "what is wrong with me/my body?"

The common humanity component of body compassion is essentially the same as that in self-compassion (Neff, 2003a), with a shift in emphasis from the global self to the physical self - the body. It is rooted in Buddhist thought and the idea that all human beings are interconnected (Barnard \& Curry, 2011). It is the recognition of this interconnectedness and the shared human experience of navigating life through the physically tangible interface of the body that is reflected in the notion of body compassion; this recognition is infused with an ease of allowing for the myriad physical manifestations of the body, in self and others. An example item from the common humanity subscale of the BCS is "When I am at my lowest during times of physical symptoms, illness or injury, I know I am not alone in feeling this way." In this case, the item with the highest loading was the same for both the undergraduate sample and the sample of women in perimenopause, "When I am frustrated with some aspect of my appearance, I try to remind myself most people feel this way at some time." Of note, of the three overarching domains of body image on which the original item development focused — appearance, health/illness, and competence/fitness — the highest loading item across two distinct samples on the common humanity factor focuses on the appearance component. This may reflect deeply embedded cultural values that persist across the lifespan. A distinction between the two samples emerges in examination of the second and third highest loading items, for the undergraduate sample both items focus on the 
fitness/competence domain of body image, for the women in perimenopause both items focus on the health/illness domain of body image. It's possible this distinction is driven by the experience of an aging body, reflected in approximately one-third of the sample of women in perimenopause reporting being diagnosed with a chronic illness.

The acceptance component of body compassion is also similar to the description of acceptance by Hayes and colleagues (2012). Acceptance in body compassion is the intentional embrace of the appearance, state of health, and function of one's body exactly as it is in the present. An example item from the acceptance subscale of the BCS is "I am accepting of my looks just the way they are," which was the highest loading item in the undergraduate sample. However, for the sample of women in perimenopause, the highest loading item was "I feel okay in my body." In this case, the emphasis on appearance does not extend across age cohorts, instead being the emphasis of the younger undergraduate sample, while the older sample of women in perimenopause seem to emphasize the state of function or health of the body.

Interestingly, the BCS exhibits excellent concurrent validity with measures expected to have associations with the BCS, with one notable exception, the appearance orientation subscale of the MBSRQ. The appearance orientation subscale measures the "extent of investment in one's appearance. High scorers place more importance on how they look, pay attention to their appearance, and engage in extensive grooming behaviors. Low scorers are apathetic about their appearance; their looks are not especially important and they do not expend much effort to 'look good'” (Cash, 2000, p. 3). One plausible explanation is that perhaps the association is spurious because a number of the items on the appearance orientation subscale are behavioral (e.g. "Before going out in public, I 
always notice how I look," "I am careful to buy clothes that will make me look my best"), while none of the items on the BCS are behavioral in nature. Upon examination of the these results, it becomes clear there is no definitive expectation of association as initially anticipated, thus generating a number of questions —-would someone higher in body compassion attend more, less, or an average amount to their appearance? What are the implications of how oriented an individual is toward their appearance in terms of how they relate to their body? Is it possible to be highly invested in one's appearance without becoming fused with the body as defining the self?

The appearance orientation subscale was negatively significantly associated with the BCS acceptance subscale. This finding makes intuitive sense with items such as "I am accepting of my looks just the way they are," "I feel okay in my body," and "I'm tolerant of my body's flaws and inadequacies." While not significant, the appearance orientation subscale did also correlate negatively with the BCS total score and defusion subscale as expected; however, it had a non-significant positive correlation with the common humanity subscale. It is possible this result, along with other findings with this subscale, points to the common humanity items as actually being a tool of social comparison rather than a reminder of interconnectedness when it comes to body image-based difficulties.

\section{Supplementary analyses}

The supplementary analyses begin the process of exploring the utility and evolution of the BCS in varying samples.

Sample comparison. To date, there are two distinct samples available for comparison of performance on the BCS—one comprised of young, apparently healthy men and women, and one comprised of women in perimenopause. The most distinctive 
demographic differences between the two samples are the inclusion of males in the undergraduate sample, mean age, and BMI. Additionally, the undergraduate sample reported significantly higher levels of body compassion as compared to women in perimenopause, as well as significantly higher levels of the common humanity and acceptance subscales of the BCS, with no significant difference between the two samples' scores on the defusion subscale (see Table 14). These key demographic differences, and significantly different levels of body compassion, point to some interesting questions about the role of age, gender and weight in how individuals relate to their bodies.

These differences may be viewed from different vantage points. It is possible that higher body compassion would be expected among a younger sample with presumably fewer of the physical ailments and challenges that often accompany the process of aging. Given the myriad of symptoms associated with perimenopause this difference may be especially poignant between these two samples. However, it may also be that this report of higher body compassion among a sample of young adults is surprising due to the emphasis of this age cohort on the body and physical appearance and the associated deleterious effects that are well-documented related to behavioral concerns such as disordered eating (Bucchianeri et al., 2013). It may also be that this younger age cohort's manner of relating to their bodies is not yet tempered by the accrual of resources and other attributes such as financial means, educational and career accomplishments, and the establishment of important relationships such as a spouse/partner and children (Markey, 2010). 
The role of gender in levels of body compassion will be important to examine in more depth as the BCS evolves. Given that level of body compassion among undergraduate males was significantly higher than that of female undergraduates, it is possible gender is the key driver of the significantly higher body compassion among the undergraduate sample as compared to the sample of women in perimenopause. This gendered expression of body compassion is in line with what we would expect based on existing literature. We know that in general, women tend to place more importance on appearance and to have higher levels of body dissatisfaction then men, although recent trends suggest men are increasingly experiencing body image disturbances (Mellor, Fuller-Tyszkiewicz, McCabe, \& Ricciardelli, 2010). It will also be important to move beyond the implications of the gender binary and to also consider gender fluidity as it relates to body compassion.

The role of weight status in levels of body compassion will also be important to examine more closely relative to body compassion. Given that the BMI of undergraduate students was significantly lower than the BMI of women in perimenopause, it is possible that weight status is the driver of levels of body compassion. Again, with the prevalence of weight stigma in western culture and the associated deleterious outcomes (Lillis, Levin, \& Hayes, 2011), perhaps the engrained messages surrounding the meaning of weight on individual worth are impacting the manner in which individuals are relating to their bodies. It is possible that higher BMI equates to being more fused with the body as the defining component of self, feeling alone in physical struggles, and lacking acceptance of the body in the context of the present moment. 
Second order CFA. The factor loadings of the first order factors (defusion $=.79$, common humanity $=.68$, acceptance $=.97$ ) on the second order factor (body compassion) support use of a total body compassion score in future studies and analyses.

\section{Exploratory analyses}

Age group comparisons. Given the sample age range of 19-67 years, it is possible that some participants met the inclusion criteria of being in perimenopause with an affirmative response to the screening question, "Are you currently experiencing persistent irregularity with 7 or more days' difference between any 2 consecutive menstrual cycles, without skipping periods? Or are you currently experiencing the persistent skipping of menstrual periods, resulting in 60 or more days' without having a period?" but were not actually in perimenopause. Some of the participants ages 40 and under may have met the screening criteria due to the side effects of various forms of hormonal contraception, not due to being in perimenopause. This raised questions regarding potential differences between those ages 40 and under and those over 40 years of age. In this sample there were significant differences between the two age cohorts in vasomotor symptoms and depression, and no significant difference in report of sleep quality.

Participants over the age of 40 reported significantly higher weekly frequency of vasomotor symptoms than did those participants ages 40 and under. Participants ages 40 and under also reported significantly higher levels of depression. However, there was no significant difference in severity of overall menopausal symptoms between the two groups or in whether they were being treated with HRT. Also, women 40 and under were significantly more likely to be treated with hormonal contraception than were those over 
40; however, given the lack of significant association between treatment with hormonal contraception and menstrual cycle irregularity this does not explain the inclusion of so many women in the younger age cohort. Similarly, there was no significant association between being treated with HC or HRT and the experience of hot flashes or night sweats. This introduces questions regarding how to differentiate between women in perimenopause (or not) when using self-report data. It may be that this "true" distinction is artificial and that it is simply important to gain an understanding of how women relate to their bodies in times of hormonal transition - regardless of the etiology. Perhaps vasomotor symptoms as the primary impetus leading women to present for treatment related to perimenopause (Sturdee, 2008) is the key distinguishing factor in menopausal status - however, this has ramifications for women who are largely asymptomatic during the menopausal transition. It is possible this developmental stage of life holds varying meanings/implications for women who are seemingly asymptomatic, or that there are other more salient features for this group that have been largely overlooked by the more biomedically focused extant literature.

Also, despite no significant difference in total body compassion between the two age cohorts, there was a significant difference in the BCS defusion subscale. Perhaps developmental considerations need to be taken into account when using the BCS. It is possible that despite the unique physical challenges inherent in the menopausal transition and with an aging body, that as one acquires life experience through the aging process there is a different understanding of self and identity such that the body is not the defining component. 
Potential predictive validity of body compassion. In determining what contribution body compassion makes to the prediction and understanding of various outcomes above and beyond more established measures of body image and selfcompassion, interesting results emerged. The defusion subscale of body compassion was retained in every final model predicting outcomes of perimenopause. This indicates the BCS consistently contributes understanding across domains.

Of note, regarding frequency of vasomotor symptoms experienced, the three body compassion subscales alone were the predictor variables when included in backward regressions with the MBSRQ-AS subscales and with the SCS subscales. Vasomotor symptoms are arguably the most purely physical characteristic related to perimenopause (Sturdee, 2008). Sleep quality, depression, and menopause-related quality of life each have elements based in the physiological, but none of these are as purely body-based experience as are vasomotor symptoms. Therefore, the result that the body compassion subscales were the only ones retained in the final models, suggests that having a mindfulness and acceptance based measure to address physical experiences is important in accurately capturing and addressing such experiences. This finding in particular suggests that, in this sample, body compassion adds something above and beyond body image in examining the relationship a woman has with her body, rather than simply various facets of cognitive appraisal she may have of her body. Similarly, in comparison with self-compassion, body compassion appears to be identifying a distinct aspect in understanding how women relate specifically to their bodies in times of physical transition, distress and discomfort, and may have a direct influence on physical outcomes - in this case, vasomotor symptoms. 
Another interesting pattern emerged in the series of regression analyses. As a predictor, the common humanity subscale of the BCS consistently effects each outcome opposite of the expected direction, opposite of the direction the defusion and acceptance subscales correlated with each outcome. In the bivariate correlations the common humanity subscale performed as anticipated, and is significantly positively correlated with the defusion and acceptance subscales. At first glance this may be assumed to indicate the presence of multicollinearity, or to suggest the BCS common humanity subscale as a suppressor variable. However, regression coefficients are not the same as correlations and they may uncover further nuance in relationships not readily seen in simple mutual associations with other predictor variables (Arah, 2008). A full understanding of these nuanced relationships will require further analyses and experimental designs beyond the scope of this initial exploration. However, as seen in the earlier discussion of the non-significant positive correlation of the common humanity subscale with the appearance orientation subscale of the MBSRQ, these results may again be pointing to the common humanity items as a tool of social comparison rather than a reminder of interconnectedness when it comes to body image-based difficulties. Further examination of the body compassion subscales as predictor variables will be important in understanding the influence of these subscales in relationship with each other and with associated residuals.

\section{Limitations}

This study represents the first cross-validation of the BCS in a sample beyond the undergraduate population. Although the factor structure was confirmed, this sample of women in perimenopause is a distinct cross-section of the larger population, thereby 
limiting the discussion of generalizability beyond this demographic. A further limitation within this sample is the potential conflation of age and symptoms of perimenopause. The broad range of ages $(19-67)$ and relatively low mean age of 42.92 suggest this sample may have participants who met criteria per the screening question, but are not actually in what would be considered a "natural" perimenopause, although they are experiencing similar symptomatology.

Additionally, the administration of measures was not counter-balanced, allowing for the possibility of order effects. It is possible participants were fatigued by the time they completed the final measures and this should be considered in interpreting the data.

Finally, inherent in the use of online self-report measures are a number of potential issues. Despite the excellent reviews of the use of Mturk in social and behavioral sciences with regard to demographic characteristics, psychometric quality of data, and reliability of scores (Rouse, 2014), it is still possible participants paid little attention and gave little thought to their answers, exhibited response bias or image management in their responses, or simply misunderstood some questions with no convenient method of asking for clarification. Also, the use of only online self-report data does not allow for establishment of concurrent validity with mixed methods, particularly biological markers such as cortisol, blood pressure, or any other physical measurement. Further research using mixed methods of measurement would address this limitation.

\section{Strengths}

Body compassion is a novel construct bridging two theoretical orientations with the goal of addressing body image-related issues in a mindfulness and acceptance-based appropriate manner. While there are a number of instruments addressing general 
mindfulness, compassion and acceptance constructs, there are limited options available specifically addressing these mindfulness and acceptance-based constructs specific to the body. The BCS successfully connects the measurement of body image and of selfcompassion into one brief, reliable and valid measure of one's relationship with the body.

In this cross-validation study of the BCS, the factor structure identified in initial development studies was replicated, and the entire scale exhibited better fit in this first real world sample. This is encouraging in the potential application of the BCS in development of targeted mindfulness and acceptance-based treatment and measurement pertaining to the body.

Another significant strength of this study is its focus on women in perimenopause. Perimenopause is a key developmental period in a woman's life which presents an everchanging milieu of physical manifestations of shifting hormones and an aging body. However, the research on perimenopause and the way women relate to their bodies is lacking, both in research and clinical applications. To date, only two studies have directly examined the role of self-compassion in the menopausal transition, and both focus on vasomotor symptoms as the primary indicator of the menopausal experience (Brown, Bryant, Brown, Bei, \& Judd, 2014; Brown, Bryant, Brown, Bei, \& Judd, 2015). Body compassion presents an opportunity to directly measure and ultimately intervene with the experience of perimenopause. Given the significance of the body in the experience of perimenopause, the current sample represents an ideal population for cross-validation of the BCS. 


\section{Future Directions}

This initial cross validation of the BCS provides justification for the continued development and cross-validation of the BCS across a range of populations. Body compassion refers to how an individual relates to her body, this human experience is relevant to the broad range of human bodily experiences. Although the concept of body compassion is ubiquitous, future cross validation may have highest utility in samples such as chronic illness, athletics, weight management, and mental health samples. As the examination of the BCS continues, it will also be important to incorporate additional forms of measurement to establish concurrent validity_particularly biological indicators such as cortisol and various fitness stress tests.

Further studies in a variety of samples will also help elucidate the nuances of the BCS and which factors and/or items are particularly salient in differing populations, as well as which are key indicators in treatment applications. Of particular interest moving forward is the role of the common humanity subscale in the BCS and an examination of the potential priming of social comparison rather than a sense of interconnectedness.

Additionally, the current study highlighted questions regarding the impact of a pre-existing condition or symptom, versus one that coincides with the onset of perimenopause, has on a woman's experience of her symptoms, and ultimately on her level of body compassion. More broadly, future research should examine if such factors impact body compassion, which in turn may translate into adaptive or maladaptive lifestyle behaviors. 
Finally, it will be important to examine body compassion as a potential mediator in intervention studies. The assessment of the impact of body compassion on outcomes may suggest treatment strategies designed to specifically address body compassion.

\section{Summary}

The present study provides support for continued use and application of the BCS as a reliable and valid measure of body compassion. Exploring the overlap of selfcompassion specific to body image-related experiences via body compassion may provide an assessment that more accurately captures and addresses the experience of relating to one's body than is currently available. This relationship with the body is relevant across a number of populations, particularly those in which the body is a salient feature of lived experience. Continued development and examination of body compassion presents an opportunity to directly measure and ultimately intervene with the experience of the constantly changing body in all of its various manifestations, from health to illness. 


\section{REFERENCES}

Abernethy, K. (2008). How the menopause affects the cardiovascular health of women. Primary Health Care, 18(6), 41-47.

Altman, J. K., Linfield, K., Salmon, P. G., \& Beacham, A.O. (2017). The body compassion scale: Development and initial validation. Manuscript submitted for publication.

Anastasi, A., \& Urbina, S. (1997). Psychological testing (7th Ed.) Upper Saddle River, NJ: Prentice Hall.

Anderson, J. C. \& Gerbing, D. W. (1988). Structural equation modeling in practice: A review and recommended two-step approach. Psychological Bulletin, 103(3), 411423. doi:10.1037/0033-2909.103.3.411

Arah, O. A. (2008). The role of causal reasoning in understanding Simpson's paradox, Lord's paradox, and the suppression effect: Covariate selection in the analysis of observational studies. Emerging Themes in Epidemiology, 5, 5. doi: 10.1186/1742$7622-5-5$

Arch, J. J., Brown, K. W., Dean, D. J., Landy, L. N., Brown, K., \& Laudenslager, M. L. (2014). Self-compassion training modulates alpha-amylase, heart rate variability, and subjective responses to social evaluative threat in women. Psychoneuroendocrinology, 42, 49-58. doi:10.1016/j.psyneuen.2013.12.018 
Avalos, L., Tylka, T. L., \& Wood-Barcalow, N. (2005). The body appreciation scale: Development and psychometric evaluation. Body Image, 2(3), 285-297. Doi:10.1016/j.bodyim.2005.06.002

Avis, N. E. (2003). Depression during the menopausal transition. Psychology of Women Quarterly, 27(2), 91-100. Doi:10.1111/1471-6402.00089

Ayers, B., Smith, M., Hellier, J., Mann, E., \& Hunter, M. S. (2012). Effectiveness of group and self-help cognitive behavior therapy in reducing problematic menopausal hot flushes and night sweats (MENOS 2): A randomized controlled trial. Menopause, 19(7), 749-759.

Baer, R. A., Smith, G. T., Hopkins, J., Krietemeyer, J., \& Toney, L. (2006). Using selfreport assessment methods to explore facets of mindfulness. Assessment, 13(1), 27-45. Doi:10.1177/1073191105283504

Bakour, H. \& Williamson, J. (2014). Latest evidence on using hormone replacement therapy in the menopause, The Obstetrician \& Gynecologist, 17(1), 20-28. Doi:10.1111/tog.12155

Barnard, L. K., \& Curry, J. F. (2011). Self-compassion: Conceptualizations, correlates, \& interventions. Review of General Psychology, 15(4), 289-304.

Doi:10.1037/a0025754

Bollen, K. A. (1989). Structural equations with latent variables. John Wiley \& Sons.

Bond, F. W., Hayes, S. C., Baer, R. A., Carpenter, K. M., Guenole, N., Orcutt, H. K., Waltz, T. \& Zettle, R. D. (2011). Preliminary psychometric properties of the Acceptance and Action Questionnaire-II: A revised measure of psychological 
inflexibility and experiential avoidance. Behavior therapy, 42(4), 676-688.

Doi:10.1016/j.beth.2011.03.007

Brach, T. (2003). Radical acceptance: Embracing your life with the heart of a Buddha. New York: Bantam.

Brooks, M., Kay-Lambkin, F., Bowman, J. \& Childs, S. (2012). Self-compassion amongst clients with problematic alcohol use. Mindfulness. doi:10.1007/s12671012-0106-5

Brown, L., Bryant, Ch., Brown, V., Bei, B., \& Judd, F. (2014). Self-compassion weakens the association between hot flushes and night sweats and daily life functioning and depression. Maturitas, 78(4), 298-303. Doi:10.1016/j.maturitas.2014.05.012

Brown, L., Bryant, C., Brown, V., Bei, B., \& Judd, F. (2015). Investigating how menopausal factors and self-compassion shape well-being: An exploratory path analysis. Maturitas, 81(2), 293-299. Doi:10.1016/j.maturitas.2015.03.001

Brown, T. A., Cash, T. F., \& Mikulka, P. J. (1990). Attitudinal body-image assessment: Factor analysis of the body-self relations questionnaire. Journal of Personality Assessment, 55(1\&2), 135-144. Doi:10.1207/s15327752jpa5501\&2_13

Browne, M. W., \& Cudeck, R. (1993). Alternative ways of assessing model fit. Sage Focus Editions, 154, 136-136.

Bucchianeri, M. M., Arikian, A. J., Hannan, P. J., Eisenberg, M. E., \& Neumark-Sztainer, D. (2013). Body dissatisfaction from adolescence to young adulthood: Findings from a 10-year longitudinal study. Body Image, 10(1), 1-15. doi: 10.1016/j.bodyim.2012.09.001. 
Buhrmester, M., Kwang, T. \& Gosling, S.D. (2011). Amazon's mechanical turk: A new source of inexpensive, yet high-quality, data? Perspectives on Psychological Science, 6(1) $3-5$.

Burt, V. K., Altshuler, L. L., \& Rasgon, N. (1998). Depressive symptoms in the perimenopause: Prevalence, assessment, and guidelines for treatment. Harvard Review of Psychiatry, 6(3), 121-132. doi:10.3109/10673229809000320

Busch, H., Barth-Olfsson, A. S., Rosenhagen, S., \& Collins, A. (2003). Menopausal transition and psychological development. Menopause, 10(2), 179-187.

Buysse, D. J., Reynolds, C. F., Monk, T. H., Berman, S. R., \& Kupfer, D. J. (1989). The Pittsburgh Sleep Quality Index: A new instrument for psychiatric practice and research. Psychiatry Research, 28(2), 193-213. Doi:10.1016/01651781(89)90047-4

Byrne, B. M. (2013). Structural equation modeling with AMOS: Basic concepts, applications, and programming ( $2^{\text {nd }}$ edition). New York: Routledge.

Callaghan, G. M., Sandoz, E. K., Darrow, S. M., \& Feeney, T. K. (2015). The body image psychological inflexibility scale: Development and psychometric properties. Psychiatry Research, 226(1), 45-52.

doi:10.1016/j.psychres.2014.11.039

Carmody, J., Crawford, S., Salmoirago-Blotcher, E., Leung, K., Churchill, L., \& Olendzki, N. (2011). Mindfulness training for coping with hot flashes: Results of a randomized trial. Menopause, 18(6), 611.

Carpenter, J. S. (2001). The hot flash related daily interference scale: A tool for assessing the impact of hot flashes on quality of life following breast cancer. Journal of 
Pain and Symptom Management, 22(6), 979-989. Doi:10.1016/S08853924(01)00353-0

Carpenter, J.S., Guthrie, K.A., Larson, J.C. Freeman, E.W., Joffe, H., Reed, S.C., Ensrud, K.E. \& LaCroix, A.Z. (2012). Effect of escitalopram on hot flash interference: A randomized, controlled trial. Fertility and Sterility, 97(6), 1399-1404.

Cash, T. (2000). MBSRQ Users Manual, Third Revision. Norfolk, VA: Old Dominion University.

Cash, T. F. (2002). Body image assessments: MBSRQ. Retrieved from http://www.bodyimages.com/assessments/mbsrq.html

Cash, T. (2008). The body image workbook: An eight-step program for learning to like your looks. New Harbinger Publications.

Cash, T. (2011). Cognitive-behavioral perspectives on body image. In Cash, T. F., \& Smolak, L. (Eds.), Body image: A handbook of science, practice, and prevention (39-47). New York: Guilford Press.

Cash, T. F., \& Lavallee, D. M. (1997). Cognitive-behavioral body-image therapy: Further evidence of the efficacy of a self-directed program. Journal of Rational-Emotive and Cognitive-Behavior Therapy, 15(4), 281-294.doi:10.1023/A:1025041926081

Casler, K., Bickel, L., \& Hackett, E. (2013). Separate but equal? A comparison of participants and data gathered via Amazon's MTurk, social media, and face-toface behavioral testing. Computers in Human Behavior, 29, 2156-2160. doi:10.1016/j.chb.2013.05.009 
Clark, L., \& Watson, D. (1995). Constructing validity: Basic issues in objective scale development. Psychological Assessment, 7, 309-319. Doi:10.1037/10403590.7.3.309

Cronbach, L.J., \& Meehl, P.E. (1955). Construct validity in psychological tests. Psychological Bulletin, 52, 281-302. Doi:10.1037/h0040957

Cohen, L. S., Soares, C. N., Vitonis, A. F., Otto, M. W., \& Harlow, B. L. (2006). Risk for new onset of depression during the menopausal transition: The Harvard study of moods and cycles. Archives of general psychiatry, 63(4), 385-390.

Cortina, J. (1993). What is coefficient alpha? An examination of theory and applications. Journal of Applied Psychology, 78(1), 98-104. Doi:10.1037/0021-9010.78.1.98

Cronbach, L.J., \& Meehl, P.E. (1955). Construct validity in psychological tests. Psychological Bulletin, 52(4), 281-302. Doi:10.1037/h0040957

Dawis, R. V. (1987). Scale construction. Journal of Counseling Psychology, 34(4), 481489. Doi:10.1037/0022-0167.34.4.481

den Tonkelaar, I., te Velde, E. R., \& Looman, C. W. (1998). Menstrual cycle length preceding menopause in relation to age at menopause. Maturitas, 29(2), 115-123.

Edwards, M. C., Cheavens, J. S., Heiy, J. E. \& Cukrowicz, K.C. (2010) A reexamination of the factor structure of the Center for Epidemiologic Studies Depression Scale: Is a one-factor model plausible? Psychological Assessment, 22(3), 711-715. Doi:10.1037/a0019917

Freeman, E. W., Sammel, M. D., Lin, H., \& Nelson, D. B. (2006). Associations of hormones and menopausal status with depressed mood in women with no history of depression. Archives of General Psychiatry, 63(4), 375-382. 
Fuh, J., Wang, S., Lee, S, Lu, S., \& Juang, K. (2006). A longitudinal study of cognition change during early menopausal transition in a rural community. Maturitas, 53, 447-453.

Gallicchio, L., Miller, S. R., Kiefer, J., Greene, T., Zacur, H. A., \& Flaws, J. A. (2015). Risk factors for hot flashes among women undergoing the menopausal transition: Baseline results from the Midlife Women's Health Study. Menopause, 22(10), 1098-1107.

Garner, D. M., Olmsted, M. P., Bohr, Y., \& Garfinkel, P. E. (1982). The eating attitudes test: Psychometric features and clinical correlates. Psychological Medicine, 12(04), 871-878. Doi:10.1017/S0033291700049163

Gibbs, Z., Lee, S., \& Kulkarni, J. (2013). Factors associated with depression during the perimenopausal transition. Women's Health Issues, 23(5), e301-e307.

Gomez, \& McLaren, S. (2015). The Center for Epidemiological Studies Depression Scale: Measurement and structural invariance across ratings of older adult men and women. Personality and Individual Differences, 75,130-134.

Doi:http://dx.doi.org/10.1016

Gorsuch, R. (1983). Factor analysis. Hillsdale, NJ: L. Erlbaum Associates.

Green, B. F. (1981). A primer of testing. American Psychologist, 36(10), 1001-1011.

Green, S. M., Key, B. L., \& McCabe, R. E. (2015). Cognitive-behavioral, behavioral, and mindfulness-based therapies for menopausal depression: A review. Maturitas, $80(1), 37-47$.

Hall, C. W., Row, K. A., Wuensch, K. L., \& Godley, K. R. (2013). The role of selfcompassion in physical and psychological well-being. The Journal of psychology, 147(4), 311-323. 
Harlow, S. D., Gass, M., Hall, J. E., Lobo, R., Maki, P., Rebar, R. W., Sherman, S., Sluss, P. M., \& de Villiers, T. J. (2012). Executive summary of the Stages of Reproductive Aging Workshop + 10: Addressing the unfinished agenda of staging reproductive aging. Climacteric, 15(2), 105-114.

Heinemann, K., Ruebig, A., Potthoff, P., Schneider, H. P. G., Strelow, F., Heinemann, L. A. J., \& Thai, D. M. (2004). The Menopause Rating Scale (MRS) scale: A methodological review. Health and Quality of Life Outcomes, 2, 45.

Huebner, E. S., \& Dew, T. (1995). Preliminary validation of the positive and negative affect schedule with adolescents. Journal of Psychoeducational Assessment, 13(3), 286-293.

Hunter, M. \& O’Dea, I. (2001). Cognitive appraisal of the menopause: The menopause representations questionnaire (MRQ). Psychology, Health \& Medicine, 6(1), 6576.

Judd, F. K., Hickey, M., \& Bryant, C. (2012). Depression and midlife: Are we overpathologising the menopause? Journal of Affective Disorders, 136(3), 199211.

Kabat-Zinn, J., Lipworth, L. \& Burney, R. (1985). The clinical use of mindfulness meditation for the self-regulation of chronic pain. Journal of Behavioral Medicine, 8, 163-90.

Kabat-Zinn, J., Massion, A. O., Kristeller, J., Peterson, L.G., Fletcher, K.E., Pbert, L., Lenderking, W.R. \& Santorelli, S.F. (1992). Effectiveness of a meditation-based stress reduction program in the treatment of anxiety disorders. American Journal of Psychiatry, 149, 936-43. 
Kelley, C. (2016). Sleep quality in midlife women: An examination of mindfulness and acceptance as predictors (Doctoral dissertation, Xavier University).

Kenny, D. A. (2015, November 24). Measuring model fit. Retrieved from http://davidakenny.net/cm/fit.htm

Kloss, J. D., Tweedy, K., \& Gilrain, K. (2004). Psychological factors associated with sleep disturbance among perimenopausal women. Behavioral sleep medicine, 2(4), 177-190.

Koch, P. B., \& Mansfield, P. K. (2004). Facing the unknown: Social support during the menopausal transition. Women \& Therapy, 27(3-4), 179-194.

Kravitz, H. M., Zhao, X., Bromberger, J. T., Gold, E. B., Hall, M. H., Matthews, K. A., \& Sowers, M. R. (2008). Sleep disturbance during the menopausal transition in a multi-ethnic community sample of women. Sleep, 31(7), 979-990.

Llaneza, P., García-Portilla, M. P., Llaneza-Suárez, D., Armott, B., \& Pérez-López, F. R. (2012). Depressive disorders and the menopause transition. Maturitas, 71(2), 120130.

Lillis, J., Levin, M. E., \& Hayes, S. C. (2011). Exploring the relationship between body mass index and health-related quality of life: A pilot study of the impact of weight self-stigma and experiential avoidance. Journal of Health Psychology, 16(5), 722727.

Lisabeth, L. D., Beiser, A. S., Brown, D. L., Murabito, J. M., Kelly-Hayes, M., \& Wolf, P. A. (2009). Age at natural menopause and risk of ischemic stroke: The Framingham Heart Study. Stroke: A Journal of Cerebral Circulation, 40(4), $1044-1049$. 
MacBeth, A., \& Gumley, A. (2012). Exploring compassion: A meta-analysis of the association between self-compassion and psychopathology. Clinical Psychology Review, 32(6), 545-552.

Markey, C. N. (2010). Invited commentary: Why body image is important to adolescent development. Journal of Youth and Adolescence, 39, 1387-1391. doi: 10.1007/s10964-010-9510-0

Mellor, D., Fuller-Tyszkiewicz, M., McCabe, M. P., \& Ricciardelli, L. A. (2010). Body image and self-esteem across age and gender: A short-term longitudinal study. Sex Roles, 63, 672-681. doi:10.1007/s11199-010-9813-3.

Messick, S. (1995). Validity of psychological assessment: Validation of inferences from persons' responses and performances as scientific inquiry into score meaning. American Psychologist, 50, 741-749.

Mishra, G. D., \& Kuh, D. (2012). Health symptoms during midlife in relation to menopausal transition: British prospective cohort study. British Medical Journal, 344(e402), 1-10. Doi:10.1136/bmj.e402

Morris, D. H., Jones, M. E., Schoemaker, M. J., Ashworth, A. \& Swerdlow, A. J. (2011). Secular trends in age at menarche in women in the UK born 1908-93: Results from the Breakthrough Generations Study. Paediatric and Perinatal Epidemiology, 25, 394-400. doi:10.1111/j.1365-3016.2011.01202.x

Morrow, P. K. H., Mattair, D. N., \& Hortobagyi, G. N. (2011). Hot flashes: A review of pathophysiology and treatment modalities. The Oncologist, 16, 1658-1664. 
Mosewich, A. D., Kowalski, K. C., Sabiston, C. M., Sedgwick, W. A., \& Tracy, J. L. (2011). Self-compassion: A potential resource for young women athletes. Journal of Sport \& Exercise Psychology, 33, 103-123.

Neff, K. (2003a). Self-compassion: An alternative conceptualization of a healthy attitude toward oneself. Self and Identity, 2(2), 85-101.

Neff, K. D. (2003b). The development and validation of a scale to measure selfcompassion. Self and Identity, 2(3), 223-250.

Neff, K. (2016). The Self-Compassion Scale is a Valid and Theoretically Coherent Measure of Self-Compassion. Mindfulness, doi:10.1007/s12671-015-0479-3

Neff, K. D., Rude, S. S., \& Kirkpatrick, K. L. (2007). An examination of self-compassion in relation to positive psychological functioning and personality traits. Journal of Research in Personality, 41(4), 908-916.

Neff, K. D. \& McGeehee, P. (2010). Self-compassion and psychological resilience among adolescents and young adults. Self and Identity, 9, 225-240.

Newhart, M. R. (2013). Menopause matters: The implications of menopause research for studies of midlife health. Health Sociology Review, 22(4), 365-376.

O’Bryant, S. E., Palav, A., \& McCaffrey, R. J. (2003). A review of symptoms commonly associated with menopause: Implications for clinical neuropsychologists and other health care providers. Neuropsychology Review, 13(3), 145-152.

Pearce, G., Thogersen-Ntoumani, C., \& Duda, J. (2014). Body image during the menopausal transition: A systematic scoping review. Health Psychology Review, 8(4), 473-489. 
Polo-Kantola, P., Saaresranta, T., \& Polo, O. (2001). Aetiology and treatment of sleep disturbances during perimenopause and postmenopause. CNS Drugs, 15(6), 445452.

Potthoff, P., Heinemann, L. A. J., Schneider, H. P. G., Rosemeier, H. P., \& Hauser, G. A. (2000). Menopause-Rating Scale (MRS): Methodological standardization in the German population. Zentralbl Gynakol, 122(5), 280-286.

Pruis, T. A., \& Janowsky, J. S. (2010). Assessment of body image in younger and older women. The Journal of General Psychology: Experimental, Psychological, and Comparative Psychology, 137(3), 225-238.

Radloff, L. S. (1977). The CES-D scale: A self-report depression scale for research in the general population. Applied psychological measurement, 1(3), 385-401.

Raes, F., Pommier, E., Neff, K. D., \& Van Gucht, D. (2011). Construction and factorial validation of a short form of the Self-Compassion Scale. Clinical Psychology \& Psychotherapy, 18(3), 250-255. Doi: 10.1002/cpp.702

Rasgon, N., Shelton, S., \& Halbreich, U. (2005). Perimenopausal mental disorders: Epidemiology and phenomenology. CNS spectrums, 10(06), 471-478.

Reynolds, F. (1999). Some relationships between perceived control and women's reported coping strategies for menopausal hot flushes. Maturitas, 32(1), 25-32.

Robinson, G. E. (2001). Psychotic and mood disorders associated with the perimenopausal period. CNS drugs, 15(3), 175-184.

Rouse, S.V. (2015). A reliability analysis of Mechanical Turk data. Computers in Human Behavior, 43, 304-307. 
Rubinstein, H. (2013). The meanings of menopause: identifying the bio-psycho-social predictors of the propensity for treatment at menopause (Doctoral dissertation, University of Cambridge).

Salzberg, S. (1997). Lovingkindness: The revolutionary art of happiness. Boston: Shambhala.

Sandoz, E. K., Wilson, K. G., Merwin, R. M., \& Kellum, K. K. (2013). Assessment of body image flexibility: the body image-acceptance and action questionnaire. Journal of Contextual Behavioral Science, 2(1), 39-48.

Schmidt, P. (2011). The 2012 hormone therapy position statement of the north american menopause society. Menopause, 19(3), 257-271. doi: 10.1097/gme.0b013e31824b970a.

Schneider, P. (2013). Hormone replacement therapy for menopause. The Journal for Nurse Practitioners, 9 (8), 541-543

Seligowski, A. V., Miron, L. R., \& Orcutt, H. K. (2014). Relations among selfcompassion, PTSD symptoms, and psychological health in a trauma-exposed sample. Mindfulness, doi:10.1007/s12671-014-0351-x

Shapiro S. (2013). Combined hormonal contraceptives and the risk of venous and arterial thromboembolism and cardiovascular death. Journal of Family Planning and Reproductive Health Care, 39(2), 89-96.

Shapiro, S. L., Brown, K. W., \& Biegel, G. M. (2007). Teaching self-care to caregivers: effects of mindfulness-based stress reduction on the mental health of therapists in training. Training and Education in Professional Psychology, 1(2), 105-115. 
Sharkey, K. M., Bearpark, H. M., Acebo, C., Millman, R. P., Cavallo, A., \& Carskadon, M. A. (2003). Effects of menopausal status on sleep in midlife women. Behavioral Sleep Medicine, 1(2), 69-80.

Shaver, J. L., \& Zenk, S. N. (2000). Review: Sleep disturbance in menopause. Journal of Women's Health \& Gender-based Medicine, 9(2), 109-118.

Sirois, F. M., Kitner, R., \& Hirsch, J. K. (2015). Self-compassion, affect, and healthpromoting behaviors. Health Psychology, 34(6), 661.

Sirois, F. M., Molnar, D. S. \& Hirsch, J. K. (2015): Self- Compassion, Stress, and Coping in the Context of Chronic Illness, Self and Identity, doi:10.1080/15298868.2014.996249

Smith, G.T., \& McCarthy, D.M. (1995). Methodological considerations in the refinement of clinical assessment instruments. Psychological Assessment, 7(3), 300-308. Doi: 10.1037/1040-3590.7.3.300

Smith-DiJulio, K., Woods, N. F., \& Mitchell, E. S. (2008). Well-being during the menopausal transition and early postmenopause: A within-stage analysis. Women's Health Issues, 18, 310-318.

Smolak, L., \& Cash, T. F. (2011). Future challenges for body image science, practice and prevention. In T. F. Cash \& L. Smolak (Eds.), Body Image: A handbook of science, practice, and prevention (pp. 470-478). New York, NY: The Guilford Press.

Soares, C. N., Prouty, J., Born, L., \& Steiner, M. (2005). Treatment of menopause-related mood disturbances. CNS spectrums, 10(06), 489-497. 
Sturdee, D. W. (2008). The menopausal hot flush—anything new? Maturitas, 60(1), 4249.

Tabachnick, B. G., \& Fidell, L. S. (2013). Using multivariate statistics (6 ${ }^{\text {th }}$ Ed.). Pearson.

Thurston, R. C. \& Joffe, H. (2011). Vasomotor symptoms and menopause: Findings from the study of women's health across the nation. Obstetrics and Gynecology Clinics of North America, 38(3), 489-501.

Tiggemann, M. (2011). Sociocultural perspectives on human appearance and body image. In Cash, T. F., \& Smolak, L. (Eds.), Body image: A handbook of science, practice, and prevention (12-19). New York: Guilford Press.

Tiggemann, M., \& Lynch, J. E. (2001). Body image across the life span in adult women: The role of self-objectification. Developmental Psychology, 37(2), 243-253.

Timur, S., \& Sahin, N. H. (2010). The prevalence of depression symptoms and influencing factors among perimenopausal and postmenopausal women. Menopause, 17(3), 545-551.

Tylka, T. L., \& Wood-Barcalow, N. L. (2015). The Body Appreciation Scale-2: Item refinement and psychometric evaluation. Body image, 12, 53-67. Doi: 10.1016/j.bodyim.2014.09.006

United States Department of Health and Human Services (2005). Facts about menopausal hormone therapy. National Institutes of Health, National Heart, Lung, and Blood Institute. Retrieved from http://www.nhlbi.nih.gov/files/docs/pht_facts.pdf Watson, D., Clark, L. A., \& Tellegen, A. (1988). Development and validation of brief measures of positive and negative affect: The PANAS scales. Journal of 
Personality and Social Psychology, 54(6), 1063. Doi:10.1037/0022-

3514.54.6.1063

Webster, J., \& Tiggemann, M. (2003). The relationship between women's body satisfaction and self-image across the life span: The role of cognitive control. The Journal of Genetic Psychology, 164(2), 241-252.

Doi:10.1080/00221320309597980

Whiteman, M. K., Staropoli, C. A., Benedict, J. C., Borgeest, C., \& Flaws, J. A. (2003). Risk factors for hot flashes in midlife women. Journal of Women's Health, 12(5), 459-472. Doi:10.1089/154099903766651586

Williams, K. A., Kolar, M. M., Reger, B. E. \& Pearson, J.C. (2001). Evaluation of a wellness-based mindfulness stress reduction intervention: A controlled trial. American Journal of Health Promotion, 15, 422. Doi:10.4278/0890-117115.6.422

Williams, J. G., Stark, S. K., \& Foster, E. E. (2008). Start today or the very last day? The relationships among self-compassion, motivation, and procrastination. American Journal of Psychological Research, 4, 37-44.

Wilson, L. F., \& Mishra, G. D. (2016). Age at menarche, level of education, parity and the risk of hysterectomy: A systematic review and meta-analyses of populationbased observational studies. PLoS One, 11(3): e0151398. doi:

10.1371/journal.pone.0151398

Woods, N. F., \& Mitchell, E. S. (2005). Symptoms during the perimenopause: Prevalence, severity, trajectory, and significance in women's lives. American Journal of Medicine, 118, S14-S24. Doi:10.1016/j.amjmed.2005.09.031 
World Health Organization. (1996). WHO Technical Report Series 866: Research on the menopause in the 1990s. Retrieved from http://whqlibdoc.who.int/trs/WHO_TRS_866.pdf

Yarnell, L. M., Neff, K. D. (2013). Self-compassion, interpersonal conflict resolutions, and well-being. Self and Identity. 2:2, 146-159. Doi:10.1080/15298868.2011. 649545. 


\section{CURRICULUM VITA}

NAME: Jennifer K. Altman

ADDRESS: Department of Psychological and Brain Sciences

317 Life Sciences Building

University of Louisville

Louisville, KY 40292

EDUCATION: Bachelor of Arts (1994-98)

University of Northern Colorado

Major: Psychology

Major: Kinesiology, Emphasis: Exercise Physiology

Major: Kinesiology, Emphasis: Social Psychological Perspectives of Sport and

Exercise

Master of Arts, Kinesiology (2002-05)

California State University Long Beach

Doctor of Philosophy, Clinical Psychology (2013-18)

University of Louisville

AWARDS: $\quad$ Stanley A. Murrell Scientist-Practitioner Award

University of Louisville

May 2017

Early Career Researcher Summer School Bursary Winner

Oxford Mindfulness Centre, Oxford, England

August 2015

Excellence in Research Award

University of Louisville Clinical Psychology Program

May 2015

Kinesiology Department Student-of-the-Year Award California State University, Long Beach

May 2004

NCAA Division II All-American Academic Athlete 1998

Psychology Department Scholar-of-the-Year Award University of Northern Colorado $1997 \& 1998$ 


\section{PUBLICATIONS:}

Altman, J. K., Zimmaro, L., \& Woodruff-Borden, J. (2017). Targeting body compassion in the treatment of body dissatisfaction: A case study. Clinical Case Studies, 16(6), 431-445. doi:10.1177/1534650117731155

Altman, J. K., Linfield, K., Salmon, P. G., \& Beacham, A. O. (2017). The body compassion scale: Development and initial validation. Journal of Health Psychology. Advance online publication. doi: 10.1177/1359105317718924

Sacamano, J., \& Altman, J. K. (2015). Beyond mindfulness: Buddha nature and the four postures in psychotherapy. Journal of Religion and Health, 55(5), 1585-1595. doi:10.1007/s10943-015-0169-4

Phillips, K.T., Altman, J.K., Corsi, K.F., \& Stein, M.D. (2012). Development of a risk reduction intervention to reduce bacterial and viral infections for injection drug users. Substance Use \& Misuse, 48(1-2), 54-64.

\section{INVITED PRESENTATIONS:}

The Language of Health, Functioning, and Disability Frazier Rehab Institute, Louisville, KY

April 20, 2017

Mindulness in Motion: Embodied Movement in Everyday Life Co-presenter with Paul Salmon, Ph.D.

Kentucky Psychological Association, Louisville, KY

September 26, 2014

Applying to Graduate Programs in Psychology, Panel Speaker Psi Chi, Department of Psychology

University of Northern Colorado 